US Army Corps of Engineers $s_{\circledast}$

Engineer Research and

Development Center

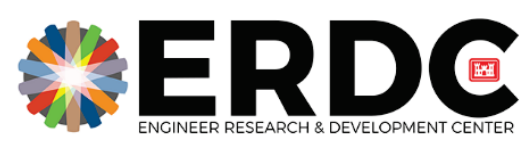

Navigation Systems Research Program

\title{
2017 Hurricane Season: Recommendations for a Resilient Path Forward for the Marine Transportation System
}

Katherine Chambers, Joshua Murphy, and Kathryn McIntosh

July 2021

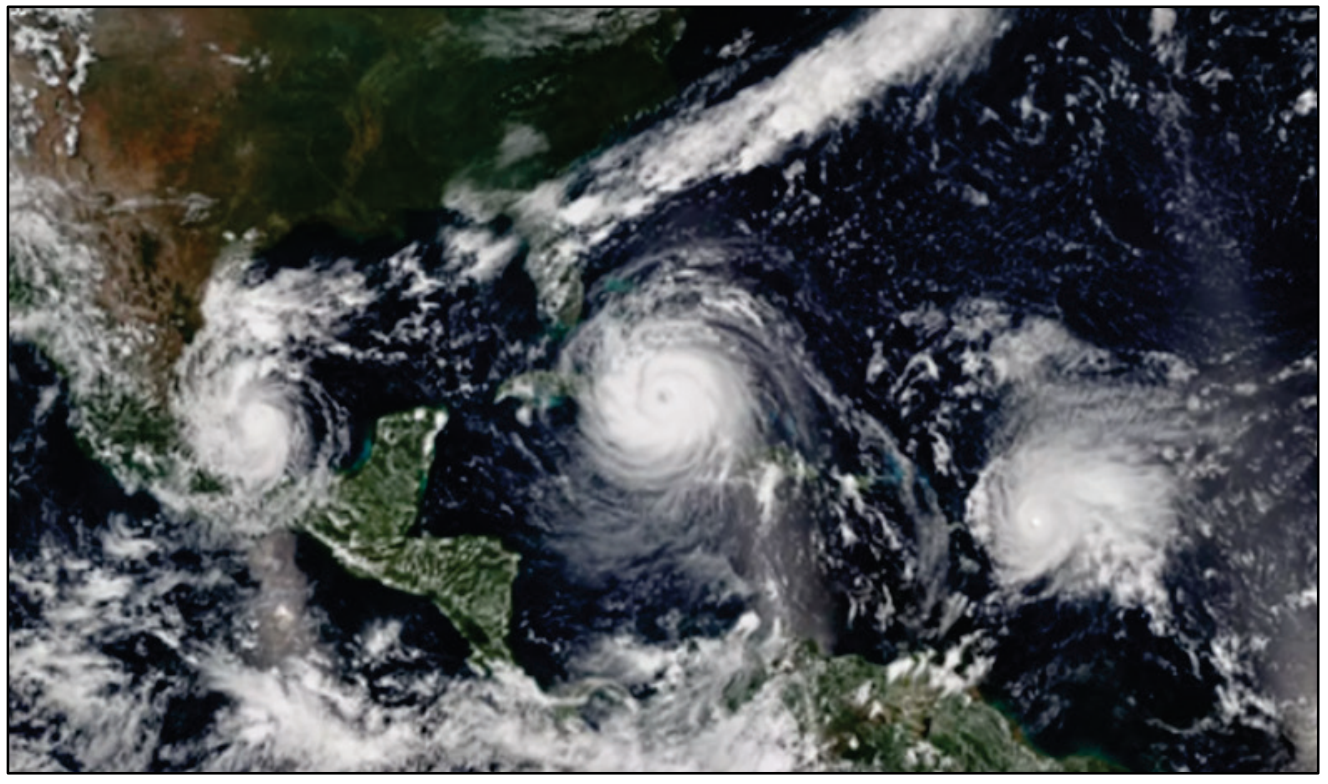


The US Army Engineer Research and Development Center (ERDC) solves the nation's toughest engineering and environmental challenges. ERDC develops innovative solutions in civil and military engineering, geospatial sciences, water resources, and environmental sciences for the Army, the Department of Defense, civilian agencies, and our nation's public good. Find out more at www.erdc.usace.army.mil.

To search for other technical reports published by ERDC, visit the ERDC online library at https://erdclibrary.on.worldcat.org/discovery. 


\section{The 2017 Hurricane Season: Recommendations for a Resilient Path Forward for the Marine Transportation System}

Katherine F. Chambers and Kathryn Mclntosh

Coastal and Hydraulics Laboratory

US Army Engineer Research and Development Center 3909 Halls Ferry Road

Vicksburg, MS 39180-6199

Joshua Murphy

NOAA Office of Coast Survey

1315 East West Highway

Silver Spring, MD 20910

Final report

Approved for public release; distribution is unlimited

Prepared for US Army Corps of Engineers

Washington, DC 20314-1000

Under Program Element No. 031391; Project No. WIC7839F5;

Funding Acct Code U4368911; AMSCO Code 031391 


\section{Abstract}

In October 2017, the Coordinating Board of the US Committee on the Marine Transportation System (MTS) tasked the MTS Resilience Integrated Action Team (RIAT) to identify the impacts, best practices, and lessons learned by federal agencies during the 2017 hurricane season. The RIAT studied the resiliency of the MTS by targeting its ability to prepare, respond, recover, and adapt to and from disruptions by turning to the collective knowledge of its members. Utilizing interagency data calls and a targeted workshop, the RIAT gauged the disruptive effect of the 2017 hurricane season and how Hurricanes Harvey, Irma, and Maria affected the operating status of at least 45 US ports across three major regions.

This report identifies recommendations to better understand how the MTS can prepare for future storms and identifies activities by federal agencies that are contributing towards resilience. Such actions include hosting early pre-storm preparedness meetings, prioritizing communication between agencies and information distribution, and maintaining or updating existing response plans. Recommendations also target challenges experienced such as telecommunication and prioritization assistance to ports and critical infrastructure. Finally, the report offers opportunities to minimize the impacts experienced from storms and other disruptions to enhance the resilience of the MTS and supporting infrastructure.

DISCLAIMER: The contents of this report are not to be used for advertising, publication, or promotional purposes. Citation of trade names does not constitute an official endorsement or approval of the use of such commercial products. All product names and trademarks cited are the property of their respective owners. The findings of this report are not to be construed as an official Department of the Army position unless so designated by other authorized documents. 


\section{Contents}

Abstract........................................................................................................................... if

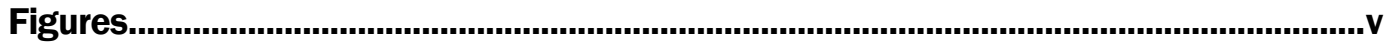

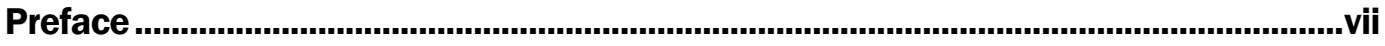

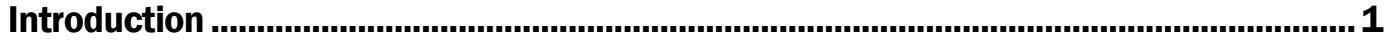

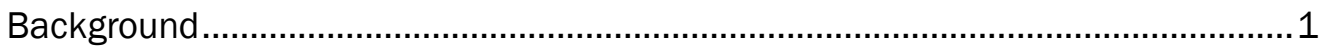

Objectives..................................................................................................

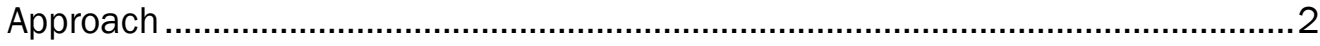

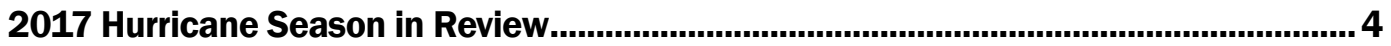

Impacts of the Marine Transportation System (MTS) on Texas, Florida, and

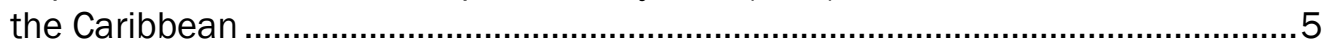

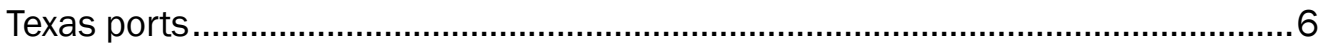

Florida ports ............................................................................................. 8

US Caribbean ports .................................................................................... 10

Hurricane impacts, pre-storm actions, challenges, and successes....................11

Hurricane Harvey ............................................................................... 12

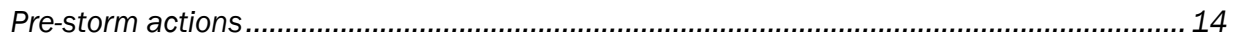

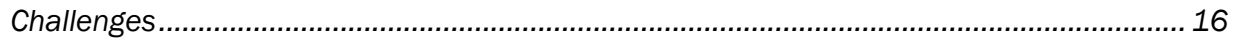

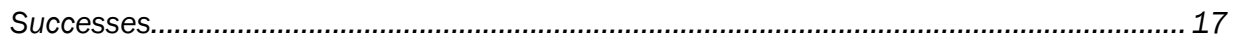

Hurricane Irma .................................................................................... 18

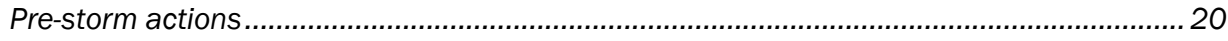

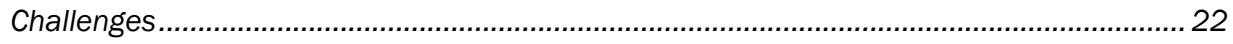

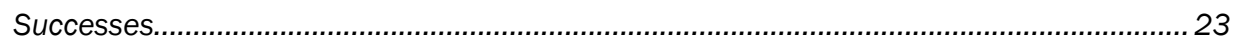

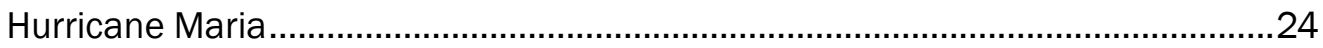

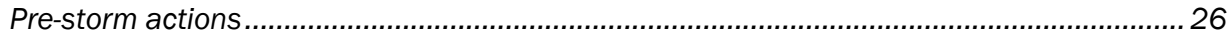

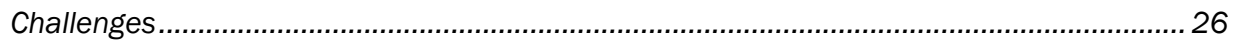

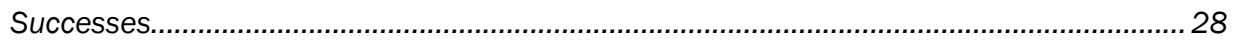

Federal best practices to restore and recover MTS operations ......................... 29

Useful information and tools for response and recovery..................................................... 32

Opportunities to enhance response and recovery ........................................................... 33

Recommendations to increase MTS resilience ............................................. 35

Preparation action recommendations .................................................................................. 36

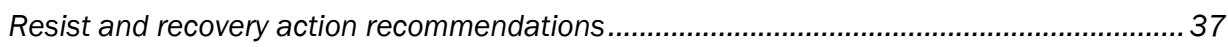

Adaptation action recommendations .............................................................................. 38

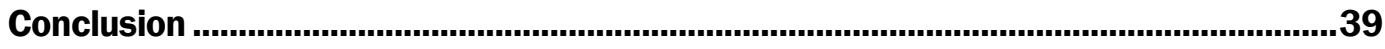

References..............................................................................................................40

Appendix A: Agencies and Offices of Workshop Attendees ........................................45

Appendix B: Interdependencies with Non-Federal Systems and Organizations..........46 
Appendix C: Learning from Previous Storms - Challenges and Lessons

Learned from Hurricane Sandy.............................................................................49

Appendix D: Marine Transportation System (MTS) Agency Response and

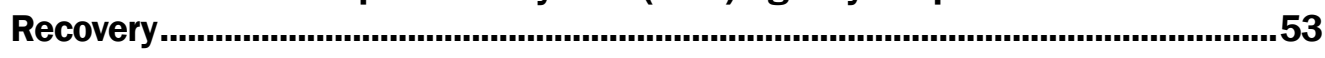

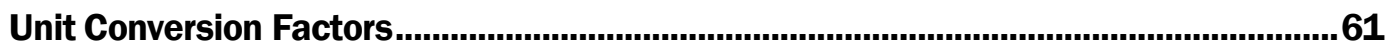

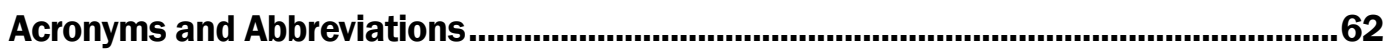

Report Documentation Page 


\section{Figures}

\section{Figures}

Figure 1. Satellite image of three hurricanes in the Atlantic at once, photographed on September 8: Katia, Irma, and Jose. (Source: NOAA/NASA).

Figure 2. Tracks of all tropical cyclones in the 2017 Atlantic hurricane season. The points display locations of the storm at 6-hour intervals, and the colors indicate wind speeds with warm colors indicating hurricanes of increasing intensity. (Source: National Hurricane Center Atlantic Hurricane database 2017)

Figure 3. Number of impacted ports across Texas, Florida, Puerto Rico, and the US Virgin Islands.

Figure 4. An illustration of the top five imports and exports handled across 21

Texas ports. Tonnage data is derived from a 5-year average from 2013-2017.

(Source: Waterborne Commerce Statistics Center, accessed via USACE Channel Portfolio Tool)

Figure 5. A distribution of average commodity types and tonnage ( $\mathrm{x} 1 \mathrm{k}$ tons) across navigation channel draft depths from 2013 to 2017. (Source: Waterborne Commerce Statistics Center, accessed via USACE Channel Portfolio Tool).

Figure 6. An illustration of the top five imports and exports handled across 15 Florida ports. Tonnage data is derived from a 5-year average from 2013-2017. (Source: Waterborne Commerce Statistics Center, accessed via USACE Channel Portfolio Tool)

Figure 7. A distribution of average commodity types and tonnage ( $\mathrm{x} 1 \mathrm{k}$ tons) across Florida navigation channel draft depths from 2013 to 2017. (Source: Waterborne Commerce Statistics Center, accessed via USACE Channel Portfolio Tool)

Figure 8. A graph of the top five imports and exports handled across Caribbean ports in USVI and Puerto Rico. Tonnage data is derived from a 5-year average from 2013 to 2017. (Source: Waterborne Commerce Statistics Center, accessed via USACE Channel Portfolio Tool.)

Figure 9. A distribution of average commodity types and tonnage ( $\mathrm{x} 1 \mathrm{k}$ tons) across navigation channel draft depths in Puerto Rico and the US Virgin Islands from 2013 to 2017. (Source: Waterborne Commerce Statistics Center, accessed via USACE Channel Port).

Figure 10. Location and port status of ports and harbors at the time of landfall for Hurricane Harvey $n$ the US Gulf Coast. (Source: US Coast Guard, Homeport)

Figure 11. Vessel signal density heatmaps (white = high; blue = low) derived from Automatic Identification System data for cargo and tanker vessel in the Gulf of Mexico before, during, and after Hurricane Harvey. (Source: USACE - ERDC, CHL)..........14

Figure 12. Location and port status of ports and harbors at the time of landfall for Hurricane Irma in the US VI, Puerto Rico, and Florida. (Source: US Coast Guard, Homeport)

Figure 13. Vessel signal density heatmaps $($ white $=$ high, blue $=$ low) derived from AIS data in the Keys before, during, and after Hurricane Irma. (Source: USACE ERDC, $\mathrm{CHL}$ ) 
Figure 14. Vessel signal density heatmaps (white = high; blue = low) derived from AIS data before, during, and after Hurricanes Irma and Maria for Puerto Rican ports and harbors. (Source: USACE - ERDC, CHL).....

Figure 15. Location and status of ports and harbors in the USVI and Puerto Rico at the time of landfall for Hurricane Maria. (Source: US Coast Guard, Homeport) ...........25

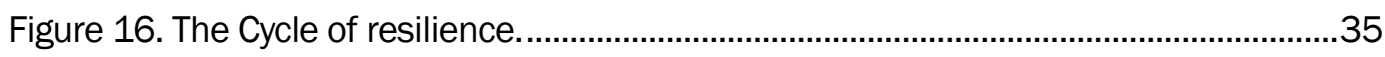

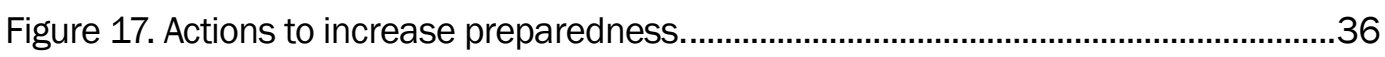

Figure 18. Actions to improve resistance and recovery......................................................37

Figure 19. Actions to adapt between disruptions...............................................................38

Figure 20. Major news headlines referred to lessons learned from Hurricane Sandy in the wake of Harvey, Irma, and Maria................................................................49 


\section{Preface}

This study was conducted for the US Army Corps of Engineers (USACE) under Program Element No. 031391; Project No. WIC7839F5; Funding Acct Code U4368911; AMSCO Code 031391. The technical monitor was Ms. Katherine Chambers.

The work was performed for the USACE Navigation Systems Research Program, in part by the Coastal Processes Branch of the Flood and Storm Protection Division, US Army Engineer Research and Development Center (ERDC), Coastal and Hydraulics Laboratory (CHL). At the time of publication of this report, Ms. Ashley Frey was Chief, Coastal Processes Branch; Dr. Cary Talbot was Chief, Flood and Storm Protection Division; Ms. Morgan Johnston was ERDC Program Manager of the Navigation Systems Research Program; Mr. Charles E. Wiggins was the ERDC Technical Director for Navigation; and Ms. Tiffany Boroughs was Chief, USACE Navigation Division. The Deputy Director of ERDC-CHL was Mr. Keith Flowers, and the Director of ERDC-CHL was Dr. Ty V. Wamsley.

This special report was prepared by an interagency team entitled the Resilience Integrated Action Team under the US Committee on the Marine Transportation System (CMTS). The interagency team consists of members from 12 different marine transportation system agencies and is co-led by Ms. Katherine Chambers and Mr. Josh Murphy. These members contributed findings, content, and preliminary review for the report. The report was then reviewed and approved by the CMTS Coordinating Board. It was initially released online on 27 December 2018. Report development was funded in part by the USACE Navigation Systems Research Program, Project No. 462579, "Navigation Systems Resilience" work unit.

The Commander of ERDC was COL Teresa A. Schlosser, and the Director was Dr. David W. Pittman. 


\section{Introduction}

\section{Background}

The US Marine Transportation System (MTS) plays a critical role in US commerce and security, facilitating the movement of over two billion tons of goods annually (NOAA NOS 2008). This critical function is often at risk as the MTS is susceptible to the impacts of weather and climate hazards, such as hurricanes. The 2017 hurricane season was a record year for the United States and its territories with four of six major hurricanes making landfall in the United States and impacting coastal communities and the infrastructure they rely upon (Figure 1). Three of these hurricanes received most of the attention for their major impacts across the Gulf Coast, Florida, and the Caribbean territories: Harvey, Irma, and Maria. Each of these hurricanes was unique and required MTS stakeholders to adjust response and recovery operations to better serve communities in need. Since these adjustments were often made ad hoc and after the major response and recovery phases were over, there is a great need to review performance, identify best practices, and ensure that the MTS agencies, owners, and operators utilize this new information to be better prepared for future storms.

Figure 1. Satellite image of three hurricanes in the Atlantic at once, photographed on September 8: Katia, Irma, and Jose. (Source: NOAA/NASA)

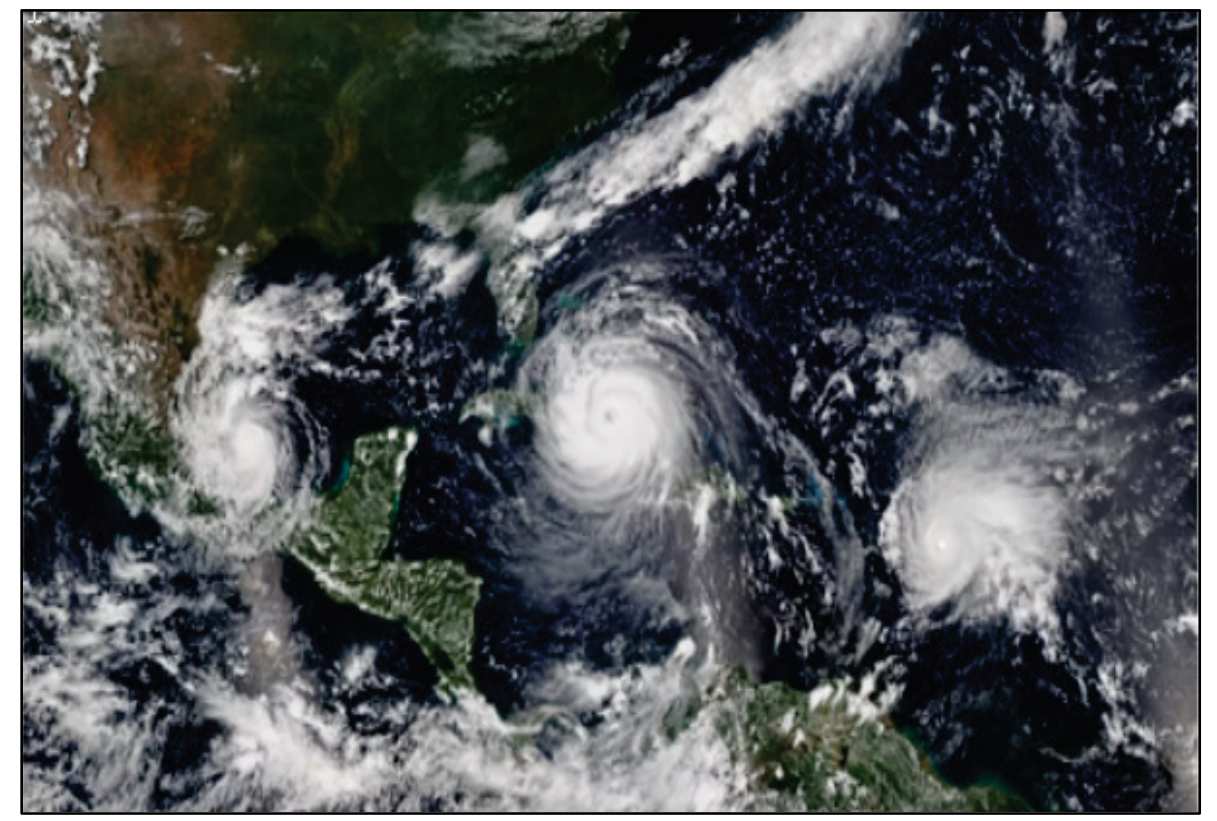




\section{Objectives}

The purpose of this report is to describe and understand the impacts, challenges, and successes of the 2017 storm season from the perspective of multiple federal agencies that manage and operate the MTS. To accomplish this, the report reviews each storm in chronological order, identifying the impacts, challenges, and successes of the federal agencies. The second objective of the report is to review this information to identify key trends that were common across all major hurricanes during the 2017 hurricane season and identify best practices and opportunities for improving resilience. The final purpose of this report is to utilize the fourstep resilience framework to identify recommendations for increasing the ability of the MTS to prepare, resist, recover, and adapt to and from future storms.

The audience for these recommendations is any federal agency with a major role in MTS recovery planning and efforts. It must be acknowledged that the federal perspective is a small part of the response and recovery following a storm. Much of the disaster recovery is the responsibility of state and local governments, nonprofits, and private industry. It is anticipated that the report will assist coordination between federal and non-federal partners' efforts in restoring the US MTS to normal operations.

\section{Approach}

The US Committee on the Marine Transportation System (CMTS) Coordinating Board (CB) directed the MTS Resilience Integrated Action Team (RIAT) to review the impacts and lessons learned from the 2017 hurricane season. The RIAT was established in September 2014 by the CMTS CB to focus on cross-federal agency knowledge, co-production, and governance to incorporate the concepts of resilience into the operation and management of the US MTS. The RIAT is composed of 12 federal agencies that manage, operate, or have an interest in the MTS and its services. Members of the RIAT and subject matter experts from within member agencies contributed to this report through their knowledge of hurricane response and recovery efforts across the MTS.

Additional MTS-related response and recovery information was acquired from a one-and-a-half-day workshop held at the US Department of Transportation in Washington, DC, in May 2018. This workshop, entitled 
Charting A Path Toward a More Resilient MTS: A Workshop to Examine Lessons Learned from the 2017 Hurricane Season, was designed to facilitate better understanding of the disruptions at US ports and their supporting maritime infrastructure from hurricanes Harvey, Irma, and Maria and was attended by federal employees involved in a variety of response and recovery operations, or research on resilience (for a list of attendee agencies and positions, see Appendix A: Agencies and Offices of Workshop Attendees). The interdependencies of these federal agencies with non-federal systems is shown in Appendix B: Interdependencies with Non-Federal Systems and Organizations. The information shared through group discussions identified key indicators, criteria, and data sources that can be applied to assess and plan for a more resilient MTS.

Much has been learned from past hurricanes like Katrina and Sandy as to how to enhance the coordination of federal and non-federal stakeholders and partners to increase the resilience and rapid recovery of the MTS to hurricanes (Appendix C: Learning from Previous Storms - Challenges and Lessons Learned from Hurricane Sandy). This report describes the importance of the MTS to impacted regions, and for each hurricane, identifies the unique impact factors, the major challenges, pre-storm actions, and successes encountered throughout the response and recovery effort. Using this information, the report aggregates existing best practices for response and recovery, identifies several opportunities to enhance response and recovery actions, and conducts an exercise to identify and recommend the most feasible and impactful actions that can be undertaken to increase the ability of the MTS to prepare, respond/recover, and adapt to future storms. 


\section{Hurricane Season in Review}

The 2017 Atlantic hurricane season was hyperactive and included 17 named storms, with four hurricanes making landfall in the US Hurricanes Harvey, Irma, Maria, and Nate (Figure 2). Figure 2 provides a visual of all the tropical cyclones in the Atlantic Ocean for 2017. This report focuses on hurricanes Harvey, Irma, and Maria, each of which holds a spot as one of the top-five most costly storms on record (NOAA NHC 2018). Ultimately, the 2017 hurricane season caused upwards of $\$ 265$ billion in damages and had major impacts on the communities, environment, and the federal navigation mission of the marine transportation system including 1,467 destroyed or damaged Aids to Navigation (navigational aids, or buoys managed by the US Coast Guard (USCG) Office of Navigation Systems; NOAA OCM 2018).

Figure 2. Tracks of all tropical cyclones in the 2017 Atlantic hurricane season. The points display locations of the storm at 6-hour intervals, and the colors indicate wind speeds with warm colors indicating hurricanes of increasing intensity. (Source: National Hurricane Center Atlantic Hurricane database 2017)

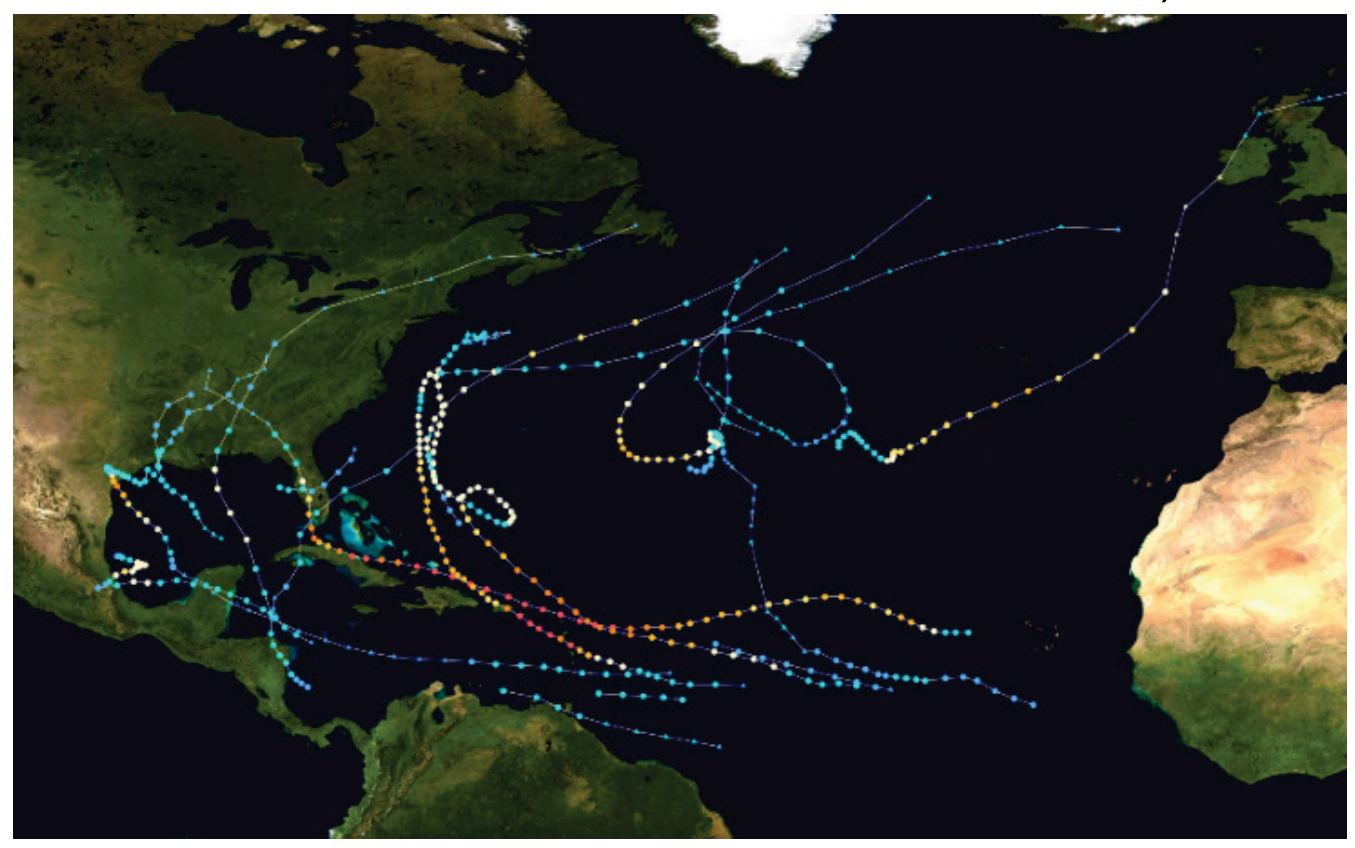

For specific information on the response and recovery actions of MTS federal agencies including the US Army Corps of Engineers (USACE), Environmental Protection Agency (EPA), USCG, Cybersecurity and Infrastructure Security Agency (CISA), Federal Emergency Management Agency (FEMA), National Oceanic and Atmospheric Administration (NOAA), and the Maritime Administration (MARAD) at the Department of 
Transportation (DOT), see Appendix D: Marine Transportation System (MTS) Agency Response and Recovery. Understanding the process of response and recovery across the impacted areas will help to inform postrecovery analysis and identify the best practices that increased the resilience of the MTS and the disaster response community.

\section{Impacts of the Marine Transportation System (MTS) on Texas, Florida, and the Caribbean}

Over the course of the 2017 hurricane season, Hurricanes Harvey, Irma, and Maria affected the operating status of at least 45 ports throughout the lower continental United States and US Caribbean territories (Figure 3). The scope of this review is limited to ports that underwent USCG port closure condition ZULU in Texas, Florida, and in the Caribbean. The Captain of the Port (COTP) enters condition ZULU when "weather advisories indicate that sustained gale force winds $\left(39-54 \mathrm{mph}^{*} / 34-37\right.$ knots) from a tropical storm or hurricane force storm" are predicted to arrive or make landfall within 12 hours of the port (US Code of Regulations 33 CFR 165.781(b)(5)). Prior to entering port condition ZULU, a port many enter condition WHISKEY when sustained gale force winds (39-54 $\mathrm{mph} / 34-47$ knots) from a tropical storm or hurricane are predicted to make landfall at the port within 72 hours; condition X-RAY is set when landfall at the port is within 48 hours Port Condition; and when sustained gale force winds are predicted within 24 hours of landfall, Port Condition YANKEE is entered (US Code of Regulations 33 CRF 165.781(b) (2-4)). While many additional ports were impacted by these storms and were required to operate under limited operating conditions such as WHISKEY, X-RAY, and YANKEE, the examination conducted in this report is limited in scope to only those ports that entered condition ZULU. The RIAT narrowed the scope of this report to focus on the impacts of a complete port closure and the subsequent reopening of the port either at full capacity or at a restricted capacity.

\footnotetext{
* For a full list of the spelled-out forms of the units of measure used in this document, please refer to US Government Publishing Office Style Manual, 31st ed. (Washington, DC: US Government Publishing Office 2016), 248-52, https://www.govinfo.gov/content/pkg/GPO-STYLEMANUAL-2016/pdf/GPOSTYLEMANUAL-2016.pdf.
} 
Figure 3. Number of impacted ports across Texas, Florida, Puerto Rico, and the US Virgin Islands.

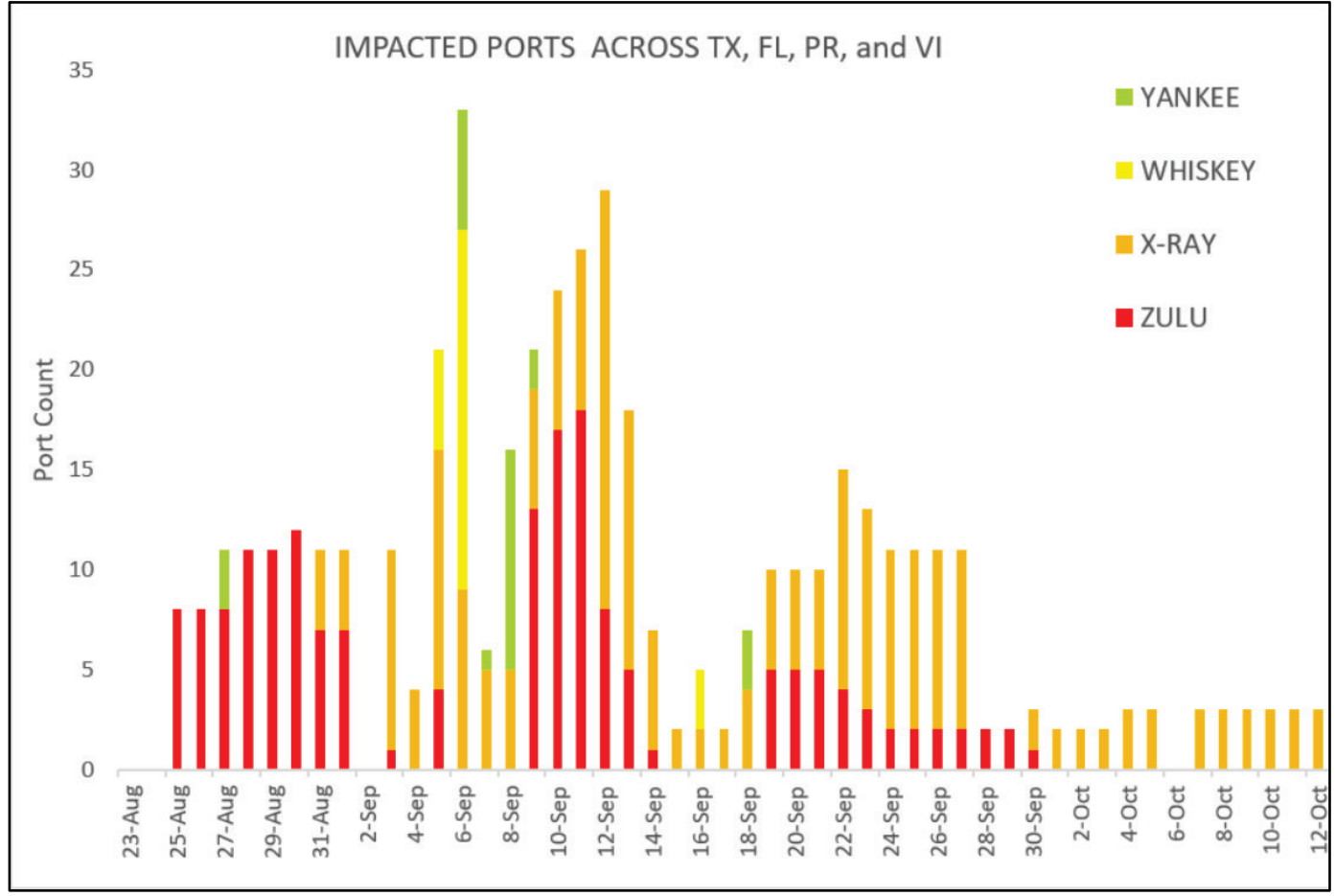

Three different regions were impacted specifically during these storms: the Gulf coast, Florida coasts, and the US Caribbean (Puerto Rico and the US Virgin Islands). When evaluating impacts to these regions, it is important to first acknowledge the role that the MTS plays for those regional economies. The MTS contributes to commerce as the major mode for US foreign trade carrying $69.3 \%$ by weight and $40.5 \%$ by value of US International merchandise in 2016 (US DOT BTS 2017). The 2017 hurricanes impacted an extraordinarily large section of US geography in a relatively short period of time. The Gulf Coast, Florida, and the Caribbean Islands are extremely reliant on the MTS for the movement of products such as petroleum, chemicals, medical supplies, and cruise tourism. The following is a summary of the commodities, tonnage, draft depths, and unique functions of the MTS for all three regions to better understand what the 2017 hurricane impacts mean in terms of industry, tourism, and regional economies.

\section{Texas ports}

In coastal Texas, the impact and importance of the MTS is visible on every horizon. Oil refineries, vessels at anchorage, the oil platforms, Gulf Coast ports, and the Gulf Intracoastal Waterway play a critical role in the 
economy of the state and the nation. Texas is home to 11 deep-draft commercial ports, six shallow-draft commercial ports, and four fishing and recreational ports. According to an economic impacts study funded by the Texas Port Association (2015), in the year 2015 these 21 ports contributed a total economic value of $\$ 1.2$ trillion in direct revenue, local purchases, and related users output for the nation (approximately $6.4 \%$ of US gross domestic product [GDP]) and generated more than 5 million jobs that are related to port activities nationwide (Texas Port Association 2015). Of these 5 million jobs, 1.6 million were created directly in the State of Texas (Texas Port Association 2015).

Much of the economic impact of these ports is owed to their great significance in the US energy industry. In 2016, Texas was the leading oil and natural gasproducing state with 29 refineries providing $30 \%$ of the total US refining capacity and producing $25 \%$ of the US marketed natural gas (US EIA 2018). These numbers are reflected in the US waterborne commerce data on top five commodities for the state (Figure 4). The vast majority of waterborne cargo tonnage moves through the 11 deep-draft ports that have an authorized channel depth greater than $30 \mathrm{ft}$. The remaining cargo tonnage is moved on the Gulf Intracoastal Waterway and through

Figure 4. An illustration of the top five imports and exports handled across 21 Texas ports. Tonnage data is derived from a 5-year average from 20132017. (Source: Waterborne Commerce Statistics Center, accessed via USACE Channel Portfolio Tool)

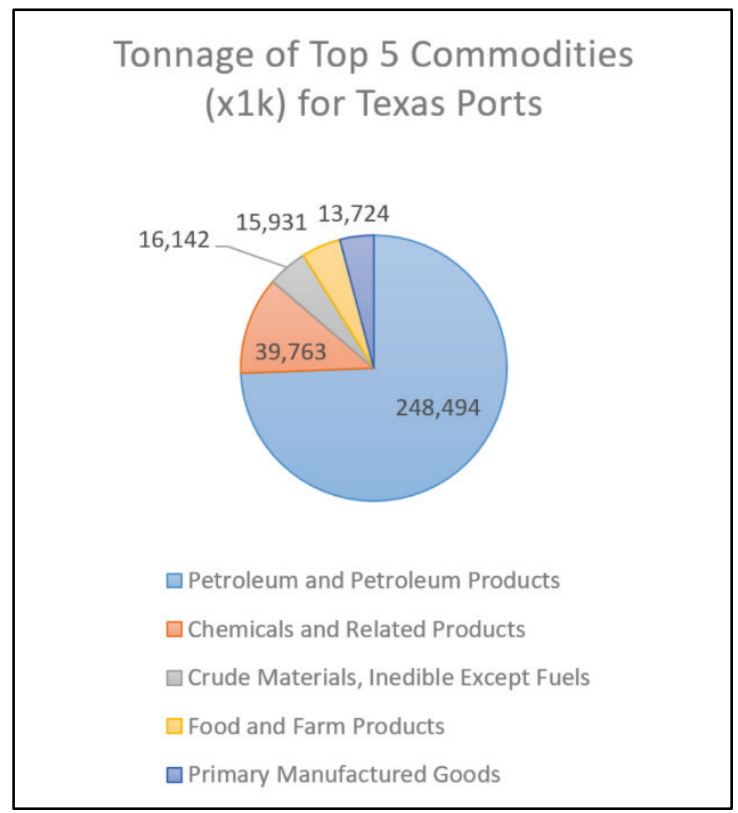
the six shallow-draft ports with drafts less than $14 \mathrm{ft}$ (Texas Department of Transportation 2017). Figure 5 illustrates the draft depth utilization for different commodity types across these port types. Overall, maintaining operational functionality at Texas ports is critical for the movement of oil and natural gas as well as continued economic growth and job security for the nation and the region. 
Figure 5. A distribution of average commodity types and tonnage ( $x 1 \mathrm{k}$ tons) across navigation channel draft depths from 2013 to 2017. (Source: Waterborne Commerce Statistics Center, accessed via USACE Channel Portfolio Tool)

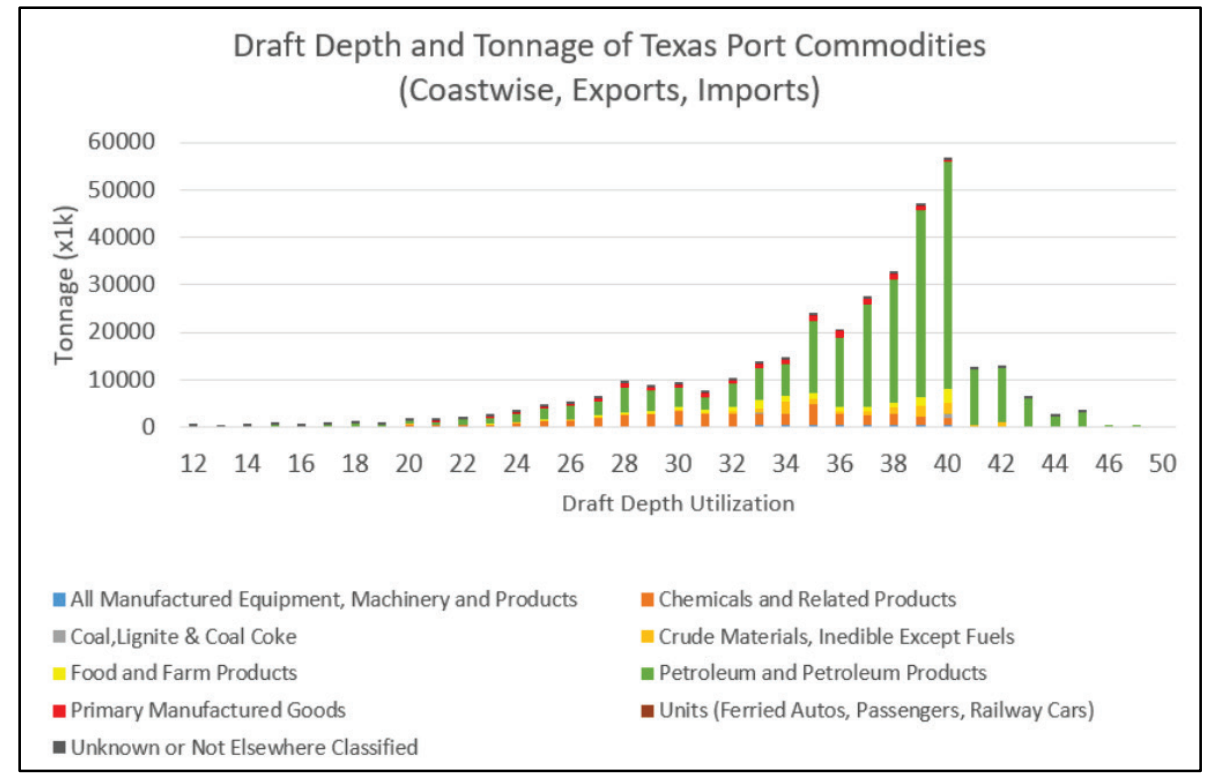

\section{Florida ports}

Florida ranked seventh among the nation's top exporting states in 2016 and is home to 15 public seaports. According to an economic analysis by Florida Seaports Council, these ports contribute $\$ 117.6$ billion in economic value and almost 900,000 direct and indirect jobs to the state via cargo and cruise operations (Florida Seaports 2011). Like Texas, most of Florida's receipts and shipments are of oil and petroleum products (Figure 6), but future developments aim towards diversifying container shipping (Florida Seaports 2011). Florida specifically receives a large amount of gasoline that is then distributed across the region. Further, Florida's top rankings in imports and exports result from the two-way
Figure 6. An illustration of the top five imports and exports handled across 15 Florida ports. Tonnage data is derived from a 5-year average from 20132017. (Source: Waterborne Commerce Statistics Center, accessed via USACE Channel Portfolio Tool)

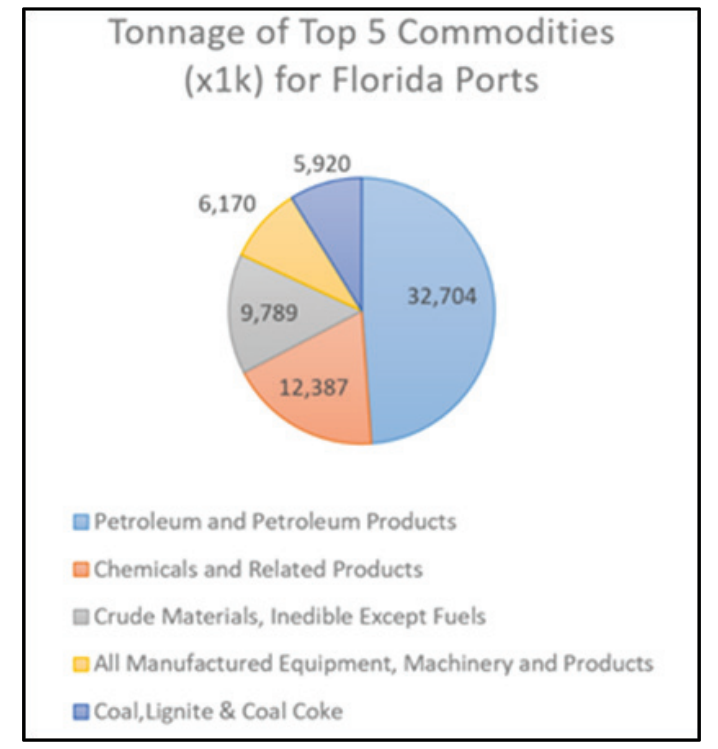


trade between the Caribbean and Latin America - a fact that can be important during hurricane season (Florida Seaports 2011). Ultimately, maritime activities in Florida contribute 13\% of the state's GDP.

To achieve the state's future development goals, the local, state, federal governments, and their interested stakeholders are spearheading investments in seaport infrastructure development projects including harbor deepening at the ports of Miami, Jacksonville, Tampa, Canaveral, and Everglades (Fort Lauderdale) and facility expansions across six other ports. Figure 7 illustrates that over $52 \%$ of Florida shipping volumes utilize draft depths greater than $32 \mathrm{ft}$, so these deepening projects will enable even larger shipments to make calls at port. These channel projects are focused on improving both the Florida import and export market through infrastructure and business climate improvements for containerized imports to the state, expanding export markets, and improving logistics once cargo arrives at port (Florida Ports Council 2018). Florida continues to operate as a key region for trade, and the developments in Florida ports bolster the economy and jobs across the state, southeastern United States, Caribbean, and Latin America (Florida Seaports 2011).

Figure 7. A distribution of average commodity types and tonnage ( $x 1 \mathrm{k}$ tons) across Florida navigation channel draft depths from 2013 to 2017. (Source: Waterborne Commerce Statistics Center, accessed via USACE Channel Portfolio Tool)

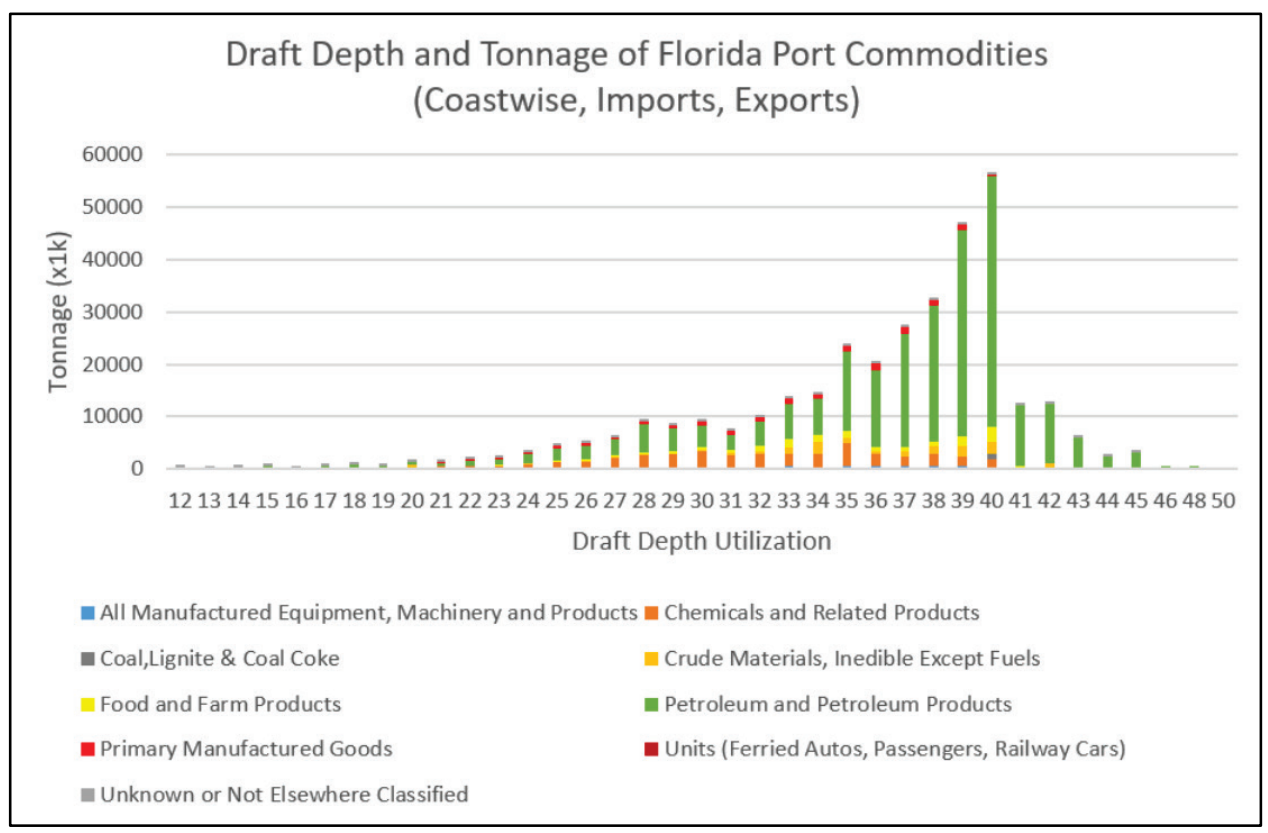




\section{US Caribbean ports}

Island communities are heavily dependent on their seaports, and their dependence on maritime trade provides both challenges and opportunities for development and expansion. The Island of Puerto Rico is densely populated and industrialized, with a robust medical manufacturing industry. The 11 ports and harbors across the island contribute a reported 3,426 direct jobs resulting in over $\$ 100$ million in wages (NOAA 2016). The top commodity by weight moving on Puerto Rico's waterways is petroleum followed closely by chemical products (Figure 8). In 2016, the mainland United States and US Virgin Islands (USVI) combined accounted for $76.4 \%$ by value (\$) of all exports and $55.5 \%$ of all imports of merchandise (Pérez et al. 2017). The top 25 commodities imported to Puerto Rico from the United States are primarily fuels and commodities related to manufacturing of pharmaceuticals and medical devices (Census Bureau 2017). If examined by value, the top exports at the Port of San Juan reflect its unique medical manufacturing sector: "medicines in individual dosages" and "plasma, vaccines, and blood." Both commodity types make up $64 \%$ of the total value of $\$ 4.13$ billion in exports from Puerto Rico (United States Trade Numbers 2018).

In the Virgin Islands, the ports are equally important to sustaining the lives and economies of its residents - in addition to supplying consumer goods to islanders, the ports are the hubs of tourism. In 2016, tourism supported approximately 5,500 jobs (12.7\% of total employment) and $31.8 \%$ of the island's GDP, with approximately 1.87 million tourists arriving by cruise ship in 2016 (Turner and Freiermuth 2017; US Virgin Islands Bureau of Economic Research 2017). The main imports by weight for the USVI and Puerto Rico are petroleum and petroleum products. However, for both Puerto Rico and USVI, manufactured equipment and 
machinery, food, and farm products were a substantial portion of the balance of the top five imports and exports. When viewed in dollar value instead of tons, the value of the manufactured equipment and machinery is greater than the value of petroleum, food and farm products, coal, and manufactured goods combined. These islands also utilize a broader spread of channel depths, with a large proportion of manufactured equipment and machinery and food and farm products utilizing $12 \mathrm{ft}$ channel depth (Figure 9).

Figure 9. A distribution of average commodity types and tonnage ( $x 1 \mathrm{k}$ tons) across navigation channel draft depths in Puerto Rico and the US Virgin Islands from 2013 to 2017. (Source: Waterborne Commerce Statistics Center, accessed via USACE Channel Port)

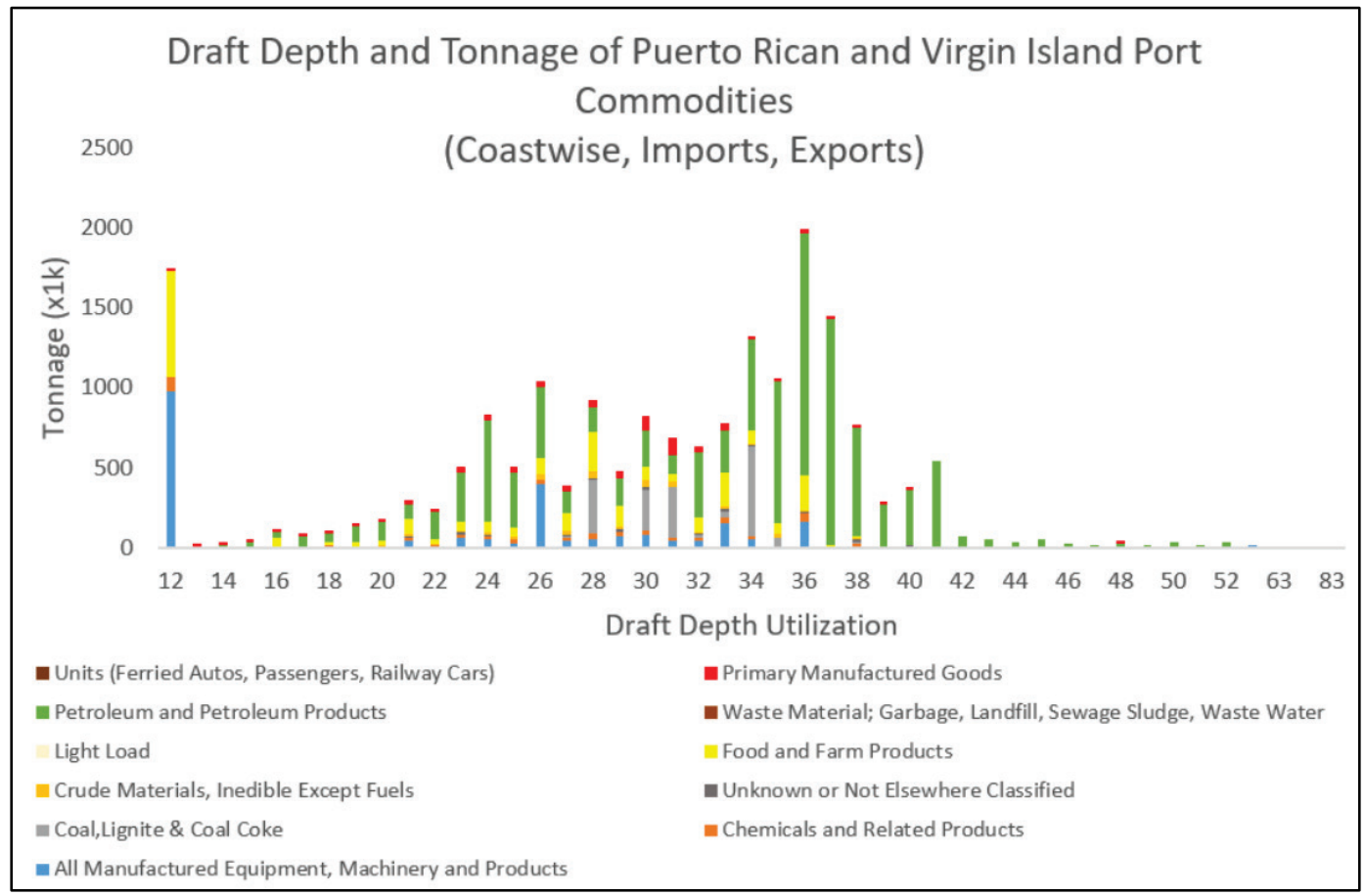

Reviewing the economic importance of ports in these three different areas offers a more comprehensive understanding of the regional and national impacts of hurricanes and major storm disruptions. This review illustrates that hurricanes affect not only the ports in these areas but the entire United States as a result of slowed activity across the supply chains of various necessary commodities.

\section{Hurricane impacts, pre-storm actions, challenges, and successes}

The following sections address three topics for each hurricane (beginning with Hurricane Harvey [Figures 10 and 11], Hurricane Irma [Figures 12 
and 13], and Hurricane Maria [Figures 14 and 15]): (1) any pre-storm preparations for the storm's arrival; (2) the impacts and unique challenges of each storm, including an analysis using the Automatic Identification System (AIS) vessel signal densities (Figure 11); and (3) the successes in response and recovery efforts. For each hurricane, an analysis of vessel signal density derived from AIS data is included (Figures 11, 13, and 14). These figures depict a significant amount of activity in and out of the major ports in each region as vessels conclude business at the port and travel to other ports or deeper anchorage to wait out the storms. This movement then comes to a standstill once the storm made landfall. For busier ports like the Houston/Galveston complex, a large queue of vessels is present in the port anchorage areas shortly after landfall waiting for the port to reopen. Port reopening is dependent on multiple factors such as the condition of the port facilities themselves, availability of power, conditions of the mooring or berthing piers, and the completion of hydrographic and bathymetric surveys to determine the level of shoaling and identify any wreckages or submerged objects. Once ports reopen, vessel movement returns to the region rapidly as demonstrated by the substantial heat signature in Figures 11 through 14 below, identified as vessels queuing outside of the port.

\section{Hurricane Harvey}

Hurricane Harvey was the second costliest hurricane in US history (after inflation) behind Hurricane Katrina in 2005 (NOAA 2018). On August 25, 2017, Hurricane Harvey made landfall along the Texas coast near Port Aransas as a Category 4 storm (Blake and Zelinsky 2018; NOAA NWS 2017). The NOAA National Hurricane Center recorded maximum sustained winds of nearly $130 \mathrm{mph}(215 \mathrm{~km} /$ hour) with higher gusts (Blake and Zelinsky 2018; NOAA NHC 2017a). During the storm, the highest maximum storm tides were observed by the US Geological Survey storm tide pressure sensors along the shore of Hynes Bay (62 miles north of Corpus Christi) where a wave-filtered water level of $9.49 \mathrm{ft}$ was recorded (Blake and Zelinsky [2018]). In addition, Harvey brought strong winds and torrential rainfall to the region. Hurricane Harvey was the most significant tropical cyclone rainfall event in US history and the highest measured storm total rainfall report was 60.8 in. in Nederland, TX (Blake and Zelinsky 2018). Storm water gauges in upper Galveston Bay on the east side of Houston measured a peak water level of $10.5 \mathrm{ft}$ mean higher high water where excessive runoff flooded the area (Blake and Zelinsky 2018). FEMA estimated that more than 19 trillion gallons of rainwater fell 
on parts of Texas, causing widespread catastrophic flooding with nearly 80,00o homes experiencing at least $18 \mathrm{in}$. of floodwater (FEMA 2017a).

On Monday, August 28, through Tuesday, August 29, eleven Texas ports underwent Port Condition ZULU (Figure 10). These ports could not reopen until shipping channels were cleared, aids to navigation were restored, and debris was removed from the navigation channel. With so much of the Texas MTS closed or operating at restricted capacity, the financial loss to merchants and the loss of products were passed on to consumers (Henry 2017). According to estimates from Sabine-Neches Navigation District officials during the 14-day period after Hurricane Harvey hit the area, the Port of Beaumont, a major exporter of the nation's petroleum products, experienced a loss of more than $\$ 1$ billion in revenue (Bloodgood 2017).

Figure 10. Location and port status of ports and harbors at the time of landfall for Hurricane Harvey $n$ the US Gulf Coast. (Source: US Coast Guard, Homeport)

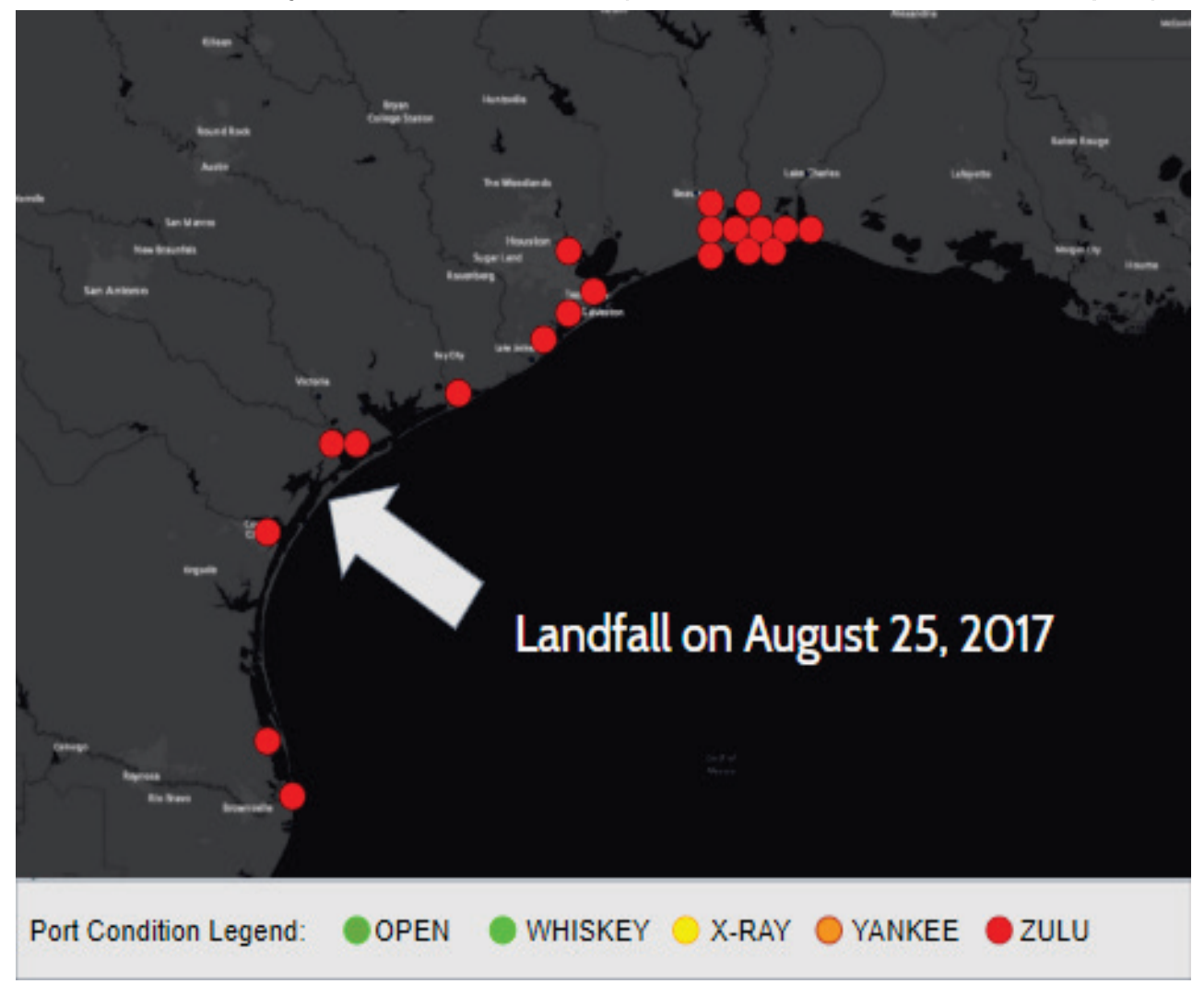

By September 22, FEMA reported that nearly 780,000 Texans had evacuated their homes, that more than 42,00o Texans were housed temporarily in 692 shelters, and that the state received an estimate of more than $\$ 1.5$ billion in federal funds in the form of assistance grants, 
low-interest disaster loans, and flood insurance advance payments (FEMA 2017a). FEMA also provided 270,916 Texan households with $\$ 571.8$ million for temporary housing, home repairs, and for other essential needs (FEMA 2017a). Vessel signal density heatmaps for the Hurricane Harvey time period are shown in Figure 11.

Figure 11. Vessel signal density heatmaps (white = high; blue = low) derived from Automatic Identification System data for cargo and tanker vessel in the Gulf of Mexico before, during, and after Hurricane Harvey. (Source: USACE - ERDC, CHL)

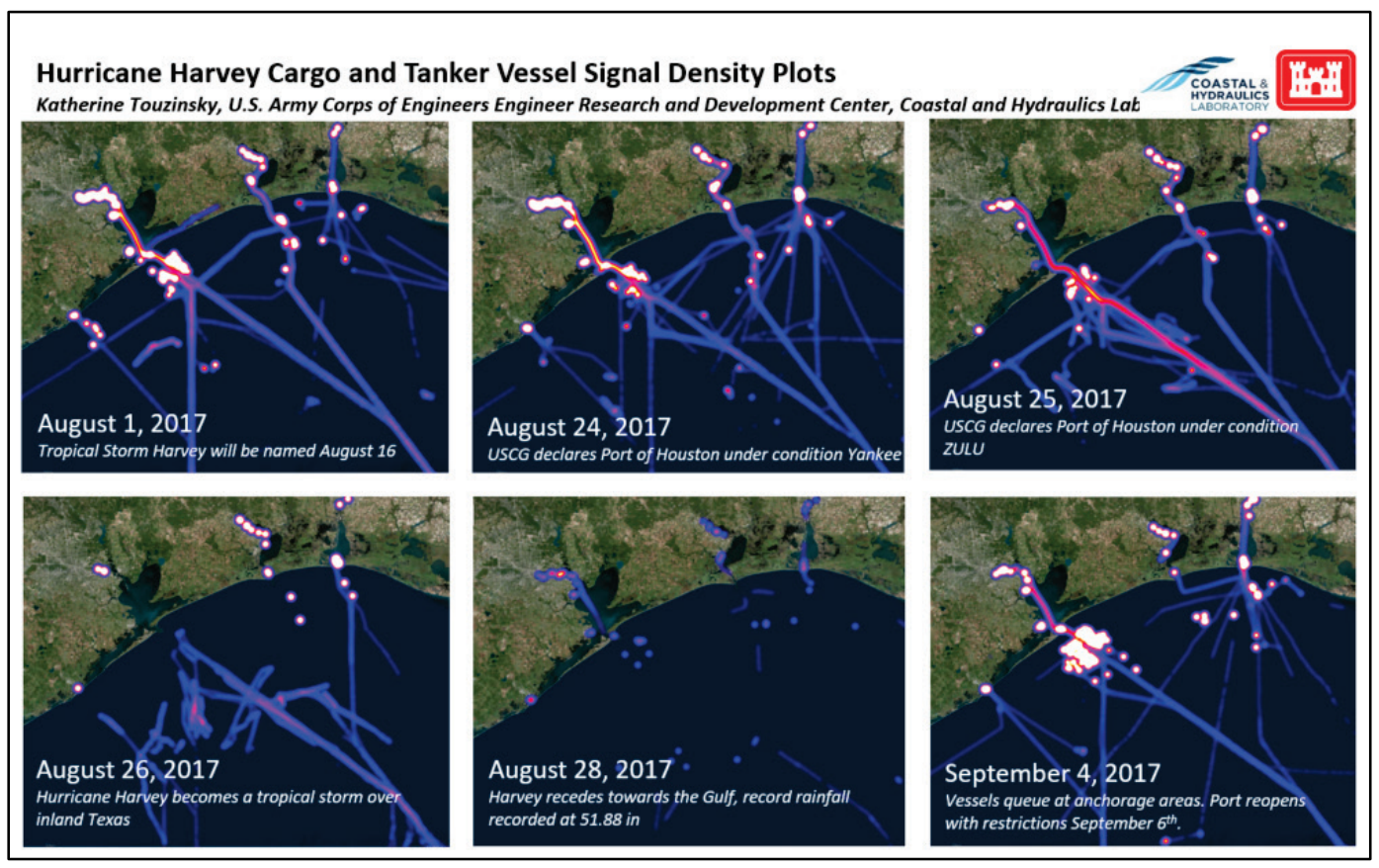

\section{Pre-storm actions}

Pre-hurricane actions for Hurricane Harvey included a broad range of activities that ultimately increased the effectiveness of response and recovery operations in the days and weeks following the major hurricanes in 2017. These actions included early communication, centralized information distribution, pre-prioritized resource placement and response materials, execution of hurricane drills and training, and the early closure of energy facilities. More details on these actions are found in the following.

Key pre-storm communication actions included establishing clear chains of communication between field units and decision makers. Two-way communication from units in the field and reporting back up through the chain of command ensured responders could manage performance expectations. Using a centralized information distribution center further assisted with the early transmission of information and reporting out to 
the field in the days leading up to Hurricane Harvey's arrival. This was not only beneficial to internal agency communications but provided a forum for most agencies involved with MTS preparation to communicate and share their own information. Additionally, the use of regionalized reporting from a common source, such as the USCG Common Assessment and Reporting Tool (CART) system, helped to guarantee all responders were operating with the same information in a timely manner. USCG Sector Houston-Galveston and the USACE Galveston District, for example, began Port Coordination Team and Texas Joint Hurricane Response Team activities as early as 22 August, sharing information among the Interagency and Port Partners and building inputs to CART. Pre-Storm communication with the NOAA National Weather Service HoustonGalveston proved to be critical as participants were able to receive expert analysis and forecast information well in advance of landfall.

The pre-prioritized placement of field units, resources, and personnel was also identified as a key pre-storm action. This included responders determining where resources were going to be stored or located before the hurricane made landfall by pre-positioning response "Go Kits" and Port Recovery Teams in locations ready for deployment at any time. Through training operations and drills conducted annually during the spring, agencies identified where and how to best place pre-prioritized resources to support response and recovery operations. Pre-identification of the right force multipliers is also key. USCG Sector Houston-Galveston worked extensively with the local USCG Auxiliary to identify members with qualifications and incident management experience that were able to be utilized in a multitude of roles within the incident command post and command center. The same can be said about the USCG reserve work force. Sector Houston-Galveston reserve force management team determined, in advance of the storm, which members would fill their critical reserve augmentation team and communicate with USCG District 8 leadership in New Orleans to ensure timely activation.

While not specifically a federal activity, the early closure of oil and gas facilities along the Gulf by industry in the days leading to Hurricane Harvey's landing helped minimize impacts to those facilities and expedited their reopening. Consistent communication before and during the storm on the status of port and facility infrastructure between industry representatives and federal agencies helped minimize impacts after the storm. Maintaining that pathway of communication on port 
infrastructure helped stabilize restoring industry operations as quickly and safely as possible.

\section{Challenges}

After making landfall, Hurricane Harvey stalled and unleashed more than 60 in. of rainfall over the southeastern part of the state of Texas, and upon landfall 20 ports and harbors in the Texas coast had been closed (Figure 10) (Blake and Zelinsky 2018). The challenges during Hurricane Harvey response and recovery efforts centered on telecommunications, impeded access to critical infrastructure due to flooding, and the lack of a centralized historic information depository.

Flooding from precipitation after Harvey made landfall caused indirect impacts to the recovery and response operations of the MTS by affecting supporting infrastructure. This historic flooding from precipitation slowed the restoration of power operations and telecommunications to ports because flooding impeded access. Flooding also damaged pre-positioned equipment and resources, requiring response agencies to organize the procurement of additional support to return ports back to operation.

Lack of data and limited availability of port condition or status information impacted knowledge management and opportunities for collaboration. First responders struggled to balance their immediate duties while answering information requests as they arose. When first responders do not have the time available to answer these requests, the current reporting structure results in a bottleneck on the availability of information regarding port status (opening, closure, reopening, or opening with restrictions) reported or shared with other agencies and the public. Responses remained hampered by limited availability to collect, collate, and share information on the status of port assess, which created a heavy demand for information from on-scene responders. Sources such as the Greater Galveston Bay Port Coordination Team and Texas Joint Hurricane Response Team proved effective in improving the availability of port condition and channel status.

Responding to information requests can place a strain on resources and having no centralized location for information across the MTS, exacerbated that issue. This challenge could be alleviated by the implementation of a centralized database that contains historic records of port status, and prior response data. These valuable historic data are 
presently not available in a centralized location and would provide information necessary when assessing lessons learned and ways to improve existing practices.

\section{Successes}

Many of the successes identified and shared by workshop participants came from putting into practice lessons learned from past hurricanes. These successes include the efficient restoration of Aids to Navigation (ATON), interagency expertise and engaging in collaborative activities, the sharing of resources between the public and private sector, adoption of local port coordination teams, and receiving active mission assignments.

The efficient restoration of ATON following Hurricane Harvey was accomplished by leveraging the Nationwide Automatic Identification System (NAIS) to transmit electronic ATON, known as AIS-ATON. Multiple AIS-ATON were broadcasted to cover damaged, missing or destroyed buoys and beacons in the affected area. AIS-ATON led to the early reopening of the Port of Corpus Christi, Texas. During this event, the USCG discovered that NAIS towers will continue to transmit AIS-ATON in the absence of internet connectivity. This capability allowed for the preplanning of AIS-ATON during subsequent storms, leading to faster reconstitution of ports and waterways.

Cross-agency communication provided the ability to turn to another agency for specific expertise not available internally (either the agency did not have the time or the knowledge base) and expedited briefing decision makers higher up the chain of command. Incorporating situational expertise from other agencies supported the rapid dissemination of best available information to decision-makers.

Engagement between the public and private sectors through the sharing of resources and needs demonstrated that the private sector could provide services to fill gaps in federal operations. This included extending the community of first responders to include private actors and the implementation of Local Port Coordination Teams.

Finally, as one of the earlier major storms to receive federal assistance, the fast and efficient delegation of mission assignments by FEMA was identified as a success for Hurricane Harvey response and recovery operations. 


\section{Hurricane Irma}

On September 6, 2017, Hurricane Irma made landfall on the Virgin Islands as a Category 5 storm with reported wind gusts of $131 \mathrm{mph}$ (The Weather Channel 2017). On September 20, 2 weeks later, Hurricane Maria arrived in St. Croix, US Virgin Islands, with sustained winds near $175 \mathrm{mph}$ (The Virgin Islands Consortium 2017). These hurricanes brought to the US Virgins Islands torrential rainfall, flooding, storm surge, destruction of homes, and electrical outages, impacting the infrastructure across the islands. During Hurricane Irma, some facilities owned by the Virgin Island Port Authority were reported damaged or destroyed. It was also reported that the Port Authority sustained more than $\$ 85$ million in hurricane-related damages to its port facilities, but despite the damage, most ports in the USVI were reopened shortly after both storms to enable emergency personnel and supplies to arrive into the territory (The Virgin Island Daily News 2017).

Figure 12 shows port conditions declared by the COPT during the height of the storm in Puerto Rico and Florida.

Figure 12. Location and port status of ports and harbors at the time of landfall for Hurricane Irma in the US VI, Puerto Rico, and Florida. (Source: US Coast Guard, Homeport)

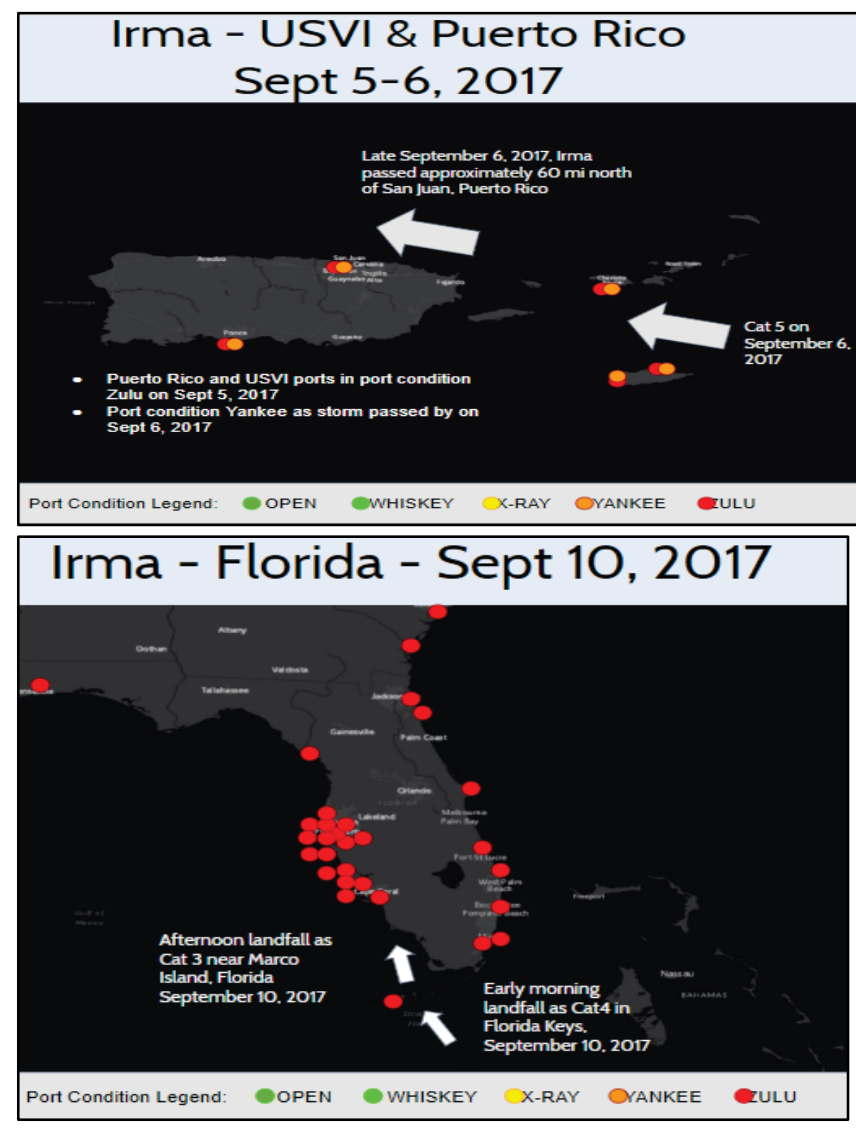

Four days after impacting the Virgin Islands, Hurricane Irma made landfall in the Florida Keys as a Category 4 storm (Figure 13; Figure 14) (NOAA NOS 2018). Irma brought sustained winds near $130 \mathrm{mph}$ in the Florida Keys and as much as 15.91 in. of rain to the St. Lucie County International Airport in Fort Pierce, 1.17 in. to Jacksonville, 10.33 in. to the Fort Myers International Airport, and 3.95 in. to Miami Beach (NOAA NHC 2017b; Brasted 2017). The impacts from Hurricane Irma also included flooding, crop loss, downed trees, power outages, destruction of homes, and disruption to the maritime industry. Hurricane Irma caused a 
portion of Florida to lose its revenue base due to the closing of ports, airports, and some highways that prevented tourists from traveling to and from Florida. For example, Royal Caribbean, Norwegian Cruise Line, Carnival, and Disney Cruise Lines canceled cruises that were set to depart from Florida.

Figure 13. Vessel signal density heatmaps $($ white $=$ high, blue $=$ low) derived from AIS data in the Keys before, during, and after Hurricane Irma.

(Source: USACE - ERDC, CHL)

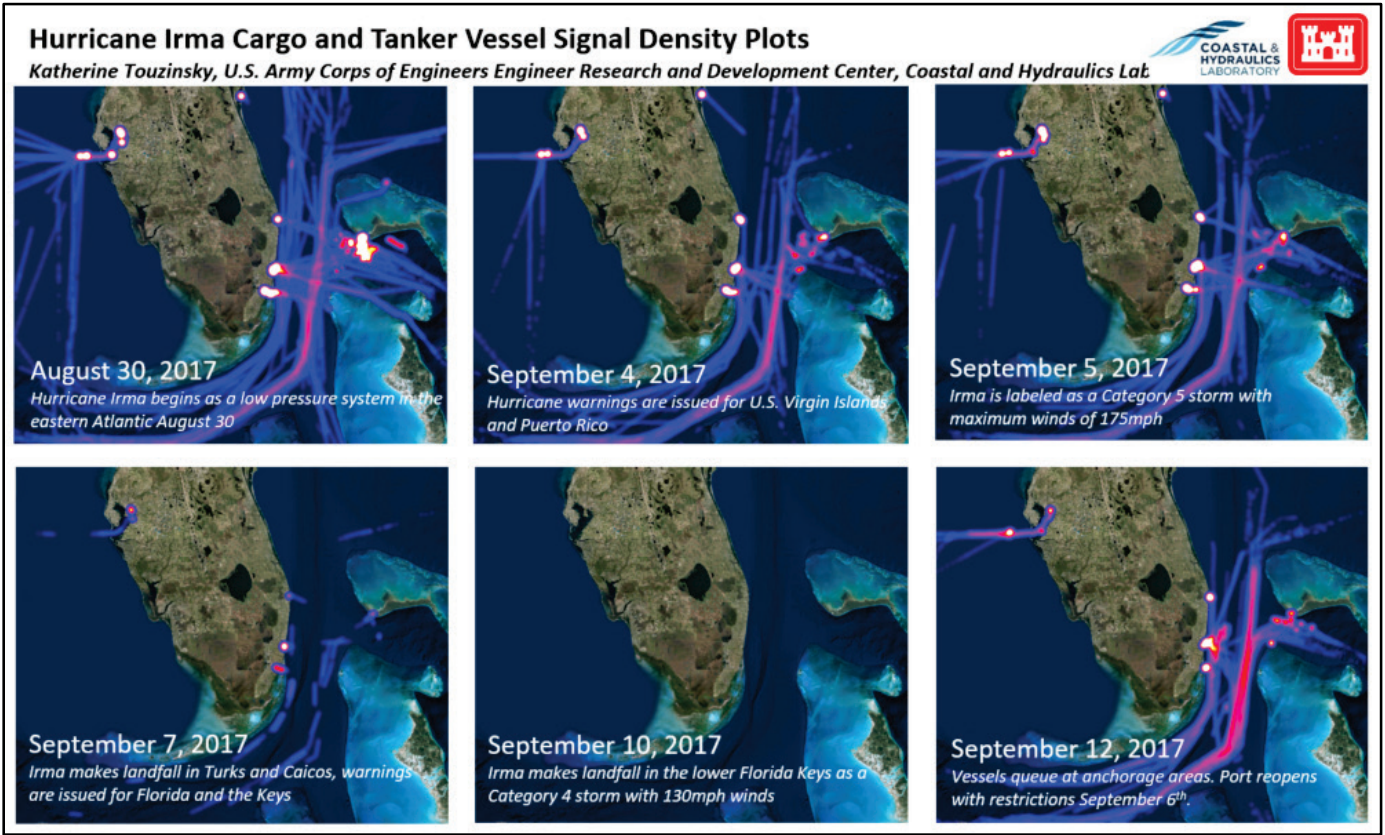

Irma was a costly event for impacted regions. As of December 2017, only $50 \%$ of USVI customers had power due in part to USACE installing over 170 generators in critical facilities, such as hospitals, water treatment facilities, and schools (FEMA 2017b). FEMA, along with the Department of Energy and others, took power restoration materials and the necessary manpower to perform the installations and provided the Virgin Islands Water and Power Authority with $\$ 110$ million in FEMA Public Assistance grants. FEMA also provided funding of more than $\$ 21$ million to help clear roads that allowed the transport of goods, supplies, and services and federal assistance to restore $75 \%$ of cell service throughout the islands (FEMA 2017b). Additionally, the Maritime Administration's Ready Reserve Force (RRF) provided sealift support to house first responders and deliver critical navigation landing equipment to the Virgin Islands to help restore flight operations on the island. As of June 2018, the state of Florida continues to recover from the devastation caused by Hurricane Irma and receives financial assistance from the US federal government. In 
June 2018, Ben Carson, the US Department of Housing and Urban Development (HUD) Secretary, announced his approval of a \$616 million disaster recovery plan to help Floridians recover from Hurricane Irma (HUD 2018). The proposed funds come from the HUD Community Development Block Grant-Disaster Recovery Program that will assist those affected by Irma to include facilitating the creation of affordable rental housing, rehabilitating housing, completing work to homes that have been partially repaired, and providing funding for the purchase of land for affordable housing development (HUD 2018).

\section{Pre-storm actions}

Just as ports on the Texas coast were beginning to reopen after Hurricane Harvey, Hurricane Irma made landfall in the USVI. Before the hurricane impacted the area, regional port and infrastructure priorities were identified that supported more efficient and effective recovery efforts. In addition, updates to existing coastal imagery and pre-arranged transportation and accommodation arrangements were actions taken before the storm that helped to minimize impacts experienced during MTS response and recovery operations. More details on these actions are found in the following.

Early communication on critical ports and supporting infrastructure with regional and local ports in Puerto Rico and the USVI in the days leading up to Hurricane Irma helped decision-makers identify where to prioritize recovery efforts. Creating a priority list assisted senior leadership determinations on where resources were required and how best to distribute responders. For the USCG, this prioritization was set by contacting the local sector (the Lieutenant or Lieutenant Commander) in the Waterways Division to determine high-risk ports. For some ports, this was accomplished by the Area Committee (AC) Marine Transportation System Recovery Unit (MTSRU) contacting the Sector MSTRU to determine the port status, and the AC MTSRU then determined the priority status of the port and assigned critical resources for that port's recovery. Further, some USCG Sectors were contacted prior to the start of the hurricane season with a request to prioritize ports and to then update their prioritization after a storm and the completion of post-storm surveys. Some of the high-priority ports would not have been otherwise prioritized without these conversations (e.g., a port that operated the only ferry to a small set of islands off the Puerto Rican coast). USCG District 7 (Atlantic area) shared a port priority list with port recovery teams in their region to 
expedite response activity and to pre-distribute Port Recovery Go Kits. Pre-storm communication helped to set out port and infrastructure prioritization by seeking out local knowledge and putting that knowledge gained to beneficial use.

Critical ATON were identified in advance between the Coast Guard Office of Navigation Systems and local Coast Guard Sectors with 287 AIS-ATON established within the forecasted cone of uncertainty. With lessons learned from Hurricane Harvey on the resiliency of NAIS towers, AIS-ATON continued transmitting despite the lack of internet connectivity.

Note that many USCG districts have an existing port prioritization list, but these lists are subject to change based on the type of disturbance experienced at the port and the ability of the USCG to respond. This means that if the USCG cannot respond to a port with higher priority because of accessibility or resource issues, a port lower in the priority list will receive assistance over the higher-prioritized port. An additional caveat is that priority can be altered based on intention (e.g., is prioritization intended to identify ports classified for security reason or tonnage, or for cruise ships), commodities, fuel, or humanitarian services to critical areas, homeland security, etc. This requires a given district's priority list must remain fluid and not standardized.

The possession of accurate pre-storm and updated coastal imagery (remote sensing and light detection and ranging) to compare with post storm imagery was a key pre-storm action assisting with MTS recovery. While not always feasible, pre-storm imagery can help responders identify impacted areas of coastline and see where resources are needed. These images and information are open to the general public and made available online as quickly as possible.

Last, pre-defined transportation and accommodation arrangements for responders eased response efforts. The arrangements before Hurricane Irma made landfall included identifying safe and easy-access equipment storage and setting up safe places for personnel to weather the storm. While these arrangements were subject to factors determined by Hurricane Irma's landfall location, the organization and planning helped place resources and personnel in as good a position to respond as quickly as possible. 


\section{Challenges}

Challenges posed by Hurricane Irma included the need to manually report power outages, post-storm debris removal, prioritizing recovery of infrastructure with competing commercial and human needs, resource and personal placement for efficient and safe response after the storm, and a general lack of available resources during the MTS response and recovery operations.

Power outages were a major challenge during response and recovery operations because most electrical systems had no monitoring system to remotely inform of outages in the grid. Consequently, most of the system had to be inspected manually. The lack of automated systems meant that identification of the non-functioning parts of the electrical grid, especially in evacuated areas, was difficult. Utilities in Florida attempted to address this issue by enlisting the aid of a firm that identified the power outages in the system by locating functioning internet provider connections. Where connections were detected, power was assumed to be available.

In the USVI, challenges persisted for months after Irma regarding how to best allocate resources between local commerce and tourism activities with other response and recovery efforts related to rebuilding critical infrastructure on the island. Balancing these interests remained problematic throughout recovery operations.

Effective pre-positioning of both equipment and accommodations to ensure personnel safety and the ability to respond efficiently once the storm passes was a significant challenge for operations managers. The geography of the Florida peninsula and the uncertainty of Hurricane Irma's cone projection made it difficult to identify locations for prepositioning of people and equipment for ready access once Irma passed.

Across impacted communities, the limited availability of refined petroleum products, including gasoline, diesel, and jet fuel, was an immediate obstacle to recovery and provided a challenge for first responders and port survey teams. The damage brought by Hurricane Harvey limited US fuel refining capacity and likely exacerbated fuel shortage issues (US EIA 2017).

Access to federal resources and funds in the response and recovery operations phase was highlighted as a major challenge. Because of the 
number of storms that occurred within a few weeks across a large geographic area, resources were spread thin. Many participants indicated that greater pre-hurricane season preparation and delivery of resources to areas historically impacted by major hurricanes would have helped reduce the resource limitations experienced post hurricane landfall.

\section{Successes}

Successful disaster response and recovery actions implemented during Hurricane Harvey were very similar to those identified during Irma. Successes included the use of the NOAA mobile integrated survey team kits, repurposing resources and equipment activated for Hurricane Harvey recovery operations, coordinating with local business advisory councils and other federal interagency partnerships, and improving status report materials.

The logistics of post-storm surveys was a challenge identified multiple times by agencies contributing to this report. For NOAA, one of the greatest successes in the 2017 season was the successful use of the mobile integrated survey team (MIST) kits when operating vessels of opportunity. Quickly providing private operators with everything they need to aid in the channel survey effort helped to quickly restore the Port of Miami back to operation.

Additionally, repurposing vessels and resources initially identified to assist with Hurricane Harvey improved the response and recovery operations for Hurricane Irma. With survey vessels and resources already making their way to impacted parts of the Gulf, those resources are able to be redirected to Florida for response more expeditiously.

Coordination with local business advisory councils and federal interagency initiatives was also a major success. During hurricanes Irma and Maria, the private sector shipped resources to Puerto Rico and to the USVI. Building strong relationships with business councils facilitated the organization and action of these operations. Further, federal interagency initiatives provided additional support in recovery operations and should be used more substantially in future response and recovery operations.

Last, there were major improvements in the flow of information through the chain of command that became more efficient as federal agencies moved from responding to Hurricane Harvey to Hurricane Irma. This 
improvement continued throughout the 2017 hurricane season and resulted in information and reporting materials that were not only efficiently and expeditiously produced but also shareable across agencies.

\section{Hurricane Maria}

Only 14 days after Hurricane Irma skirted the island, Hurricane Maria made landfall in Puerto Rico on September 20, 2017, as a Category 5 storm and ravaged the island for more than 30 hours, with winds reaching speeds of $175 \mathrm{mph}$ and precipitation amounts that caused widespread catastrophic flooding (Steenson 2017). Maria has been reported as the third costliest hurricane in US history, behind Harvey and Katrina (NOAA 2018). Maria crippled infrastructure systems across the island. While Hurricane Irma skirted the northern coast of the island, Maria was a direct hit and caused major impacts across the MTS (Figure 14). In 2017, Puerto Rico's annual exports totaled $\$ 15.9$ billion. That was a $20.7 \%$ drop from the previous year. Almost all of the decline in exports appears to be due to the impacts of Hurricane Maria during the fourth quarter of 2017 (US DOL BLS 2018). The pharmaceutical industry represents approximately $26 \%$ of Puerto Rico's gross domestic product and 13 of the top 20 prescription medications sold in the United States are manufactured in Puerto Rico (US DOL BLS 2011; Schmider 2010). Puerto Rico's top three exports of pharmaceutical and medicine manufacturing, basic chemical manufacturing along with medical equipment and supplies manufacturing accounted for approximately $86.6 \%$ of the territory's total exports in 2017 (US DOL BLS 2018). Destruction caused by Maria resulted in the closing of factories, and slowed production resulted in critical shortages in the United States of certain pharmaceutical and medical supplies, such as intravenous bags (Armour and Burton 2018). 
Figure 14. Vessel signal density heatmaps (white = high; blue = low) derived from AIS data before, during, and after Hurricanes Irma and Maria for Puerto Rican ports and harbors. (Source: USACE - ERDC, $\mathrm{CHL}$ )

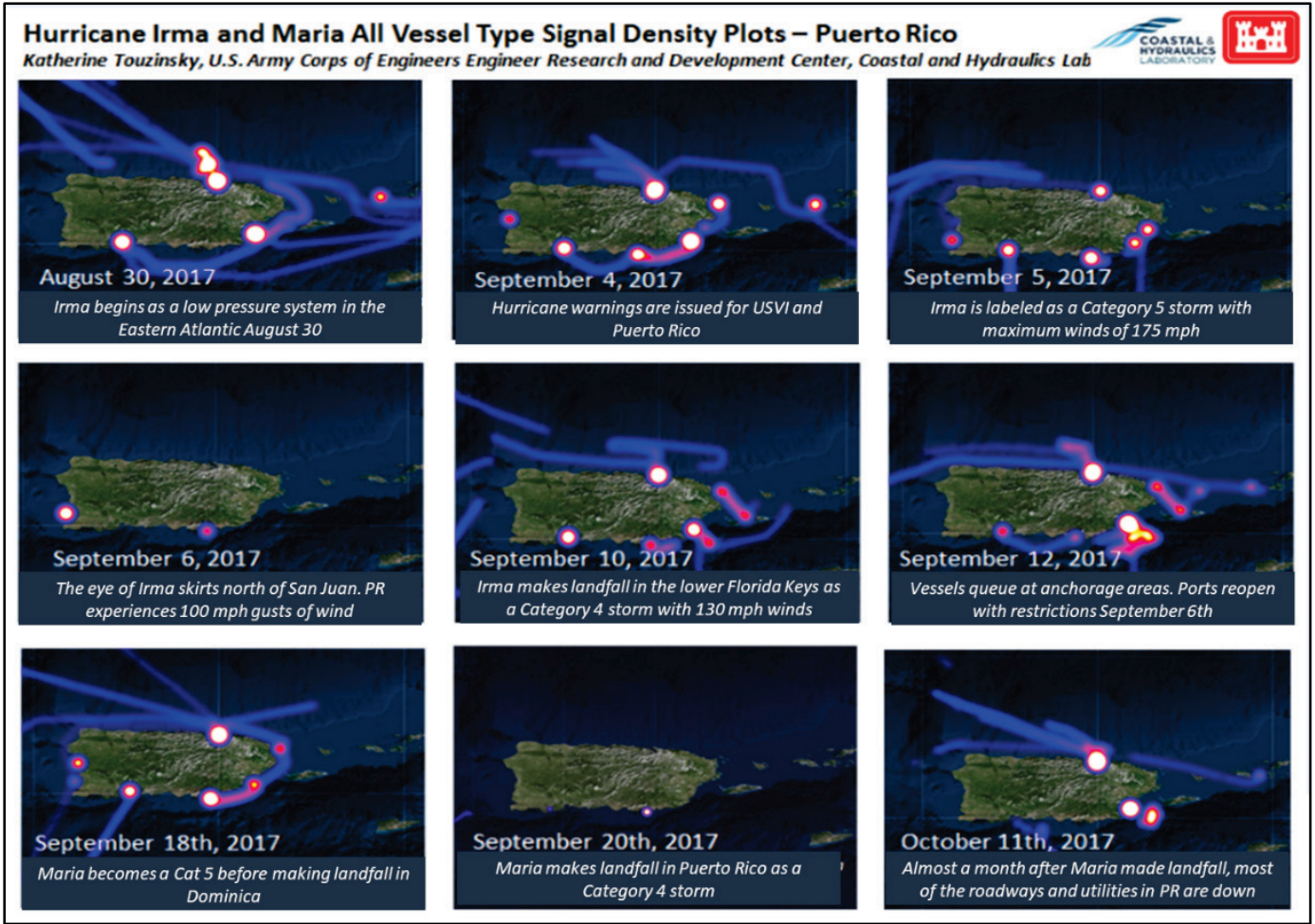

During Hurricane Maria, the Port of San Juan Harbor remained in ZULU status for 5 days while the Ponce Harbor remained in ZULU status for 11 days (Figure 15). The closures were due to many factors including flood and wind damage from torrential rainfall, storm surge, and prolonged winds to homes, the electrical grid, transportation systems, and communication networks.

The USACE, FEMA, and the Federal Communications
Figure 15. Location and status of ports and harbors in the USVI and Puerto Rico at the time of landfall for Hurricane Maria.

(Source: US Coast Guard, Homeport)

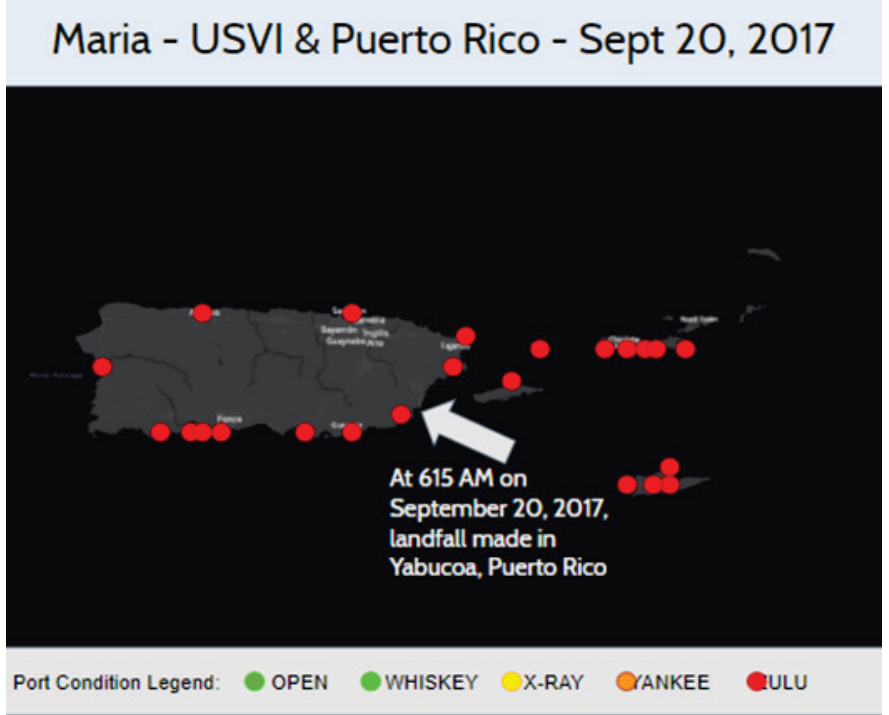

Commission (FCC) have played key roles in facilitating the provision of federal financial assistance to Puerto Rico. In March 2018, the FCC 
unveiled a \$954 million plan to restore and expand communications networks in both Puerto Rico and the USVIs (FCC 2018). In April 2018, USACE announced it would provide additional resources to expedite emergency power restoration. This was done by increasing the value of an electrical restoration contract from $\$ 370$ million to a new total of $\$ 510.6$ million. This provided for continued restoration efforts throughout May 2018 (USACE 2018c).

\section{Pre-storm actions}

Many of the actions identified during Hurricanes Harvey and Irma also helped reduce impacts to the MTS during Hurricane Maria (e.g., early or pre-identification of critical infrastructure and facilities for manufacturing). In Puerto Rico, building on the existing platform for response and recovery operations initiated during Hurricane Irma helped facilitate additional response and recovery operations post-Maria.

For Maria, first responders and local surveyors with Spanish language skills were critical for overcoming language barriers.

Second, providing first responders with transportation to conduct inspections required specialized vehicles to overcome issues with debris and impacted roads. This action facilitated fast surveys of storm damage.

Finally, to avoid burdening the local community, alternative housing opportunities for responders were initiated. The NOAA vessel Thomas Jefferson was deployed to Puerto Rico to conduct surveys and was also utilized to provide housing services for responders. As done for Harvey and Irma, MARAD sent ships to support first responders with recovery. The Empire State VI, the training ship for the State University of New York Maritime College and the Massachusetts Maritime Academy's Kennedy served as berthing, feeding, and supply points for first responders on the US territory (Workboat 2017). These ships are part of the MARAD National Defense Reserve Fleet.

\section{Challenges}

Hurricane Maria directly impacted the Island of Puerto Rico, destroying an estimated $85 \%$ of the island's power grid infrastructure and generating over 4 million $\mathrm{yd}^{3}$ of debris that clogged roadways and slowed restoration efforts. The logistical issues of bringing rebuilding supply chains to the 
island increased pressure on shipping operations and the procurement of supplies. While the domestic shipping companies were more than able to meet capacity requirements in the aftermath of Maria, landside operations in Puerto Rico were significantly damaged such that relief aid could not initially be moved from the ports to inland destinations, creating significant backlogs at the ports. With hurricanes Harvey and Irma, and wildfires raging through the western United States, federal emergency operations were stretched to their capacity, and the demand for power restoration equipment outweighed the supply (Ferris 2018). Major challenges for the recovery of the MTS also included a lack of available warehouse space and capacity to run operations. A logistical issue was the need for responders to be fully self-sufficient due to the breakdown in the supply chain systems on the island. A third challenge was the need to respond and recover the MTS as rapidly as possible in an environment that was receiving intense and often negative press coverage.

Commercial ports in Puerto Rico were gridlocked following Hurricane Maria. A key factor causing this was the buildup of cargo from damaged or nonfunctional roadways and a lack of space for shipping operations and warehousing. To address the need for additional capacity, FEMA set up operations at an unused naval base. This created a new set of challenges as a post-storm channel survey was required to determine which vessels could utilize the installation based upon any draft restrictions. Further, to utilize the base fully, all waterways and intermodal networks out of the base needed to be operational. Efforts to bring the base up to operational standards required the allocation of limited resources and took time. The need to utilize and refurbish the naval base highlighted the lack of redundancy and of available space to adequately pre-position necessary post-disaster resources. This is not an isolated example. Consistently across the island, response and recovery was hindered by a lack of capacity.

Debris removal after Hurricane Irma but before Hurricane Maria made landfall was another major challenge. In Puerto Rico, there was limited coordination of the removal of debris off the island in-between hurricane Irma and Maria and debris pileup slowed down restoration efforts.

Responders were also required to arrive in Puerto Rico and the USVI with all of their own resources. With so much of the island's infrastructure in disrepair, self-sufficiency of early responders was critical to avoid placing any additional burden on island communities. This meant arriving on the island with their own camping supplies and food sources. 
Negative press and politics of recovery on the island was also a major challenge. While responders waited for power grid and reconstruction materials to arrive on island after the storm, substantial negative press was generated. To prevent delays and avoid external criticism, contracts with carriers for material and resources, and space to store them upon arrival, should be set up prior the start of the hurricane season.

\section{Successes}

Hurricane Maria shared many of the same successes identified during Hurricanes Harvey and Irma. The emergency response community was actively responding to Harvey, Irma, and wildfires in the western United States during the arrival of Maria. These consecutive disasters required innovation and flexibility on the part of federal agencies.

Interagency collaboration and the sharing of information was a very significant achievement. Hurricane Maria prompted agencies to closely collaborate prior to the event, during and post-event in terms of discussion of lessons learned, challenges addressed, and other ancillary observations related to the response and recovery after the storm. Collaboration among agencies should be included in pre-storm operations moving forward.

National AIS infrastructure was utilized to broadcast synthetic AIS-ATON to help facilitate the reopening of the Port of San Juan. These AIS-ATON rapidly provided an acceptable level of navigation support while the system was returned to full capacity. Normally, the process to restore the physical ATON buoy system requires hours to days, but AIS-ATON created a temporary operating system within minutes and allowed Coast Guard units to rapidly cross-check the location of ATON buoys in relationship to the AIS-ATON once the storm had passed.

The domestic shipping lines met the challenge of providing continued service to Puerto Rico. The aftermath of Hurricane Maria, while devastating, highlighted the reliability of US domestic shipping services despite the worst of conditions, accordingly demonstrating that the domestic shipping companies can play a significant role in disaster recovery. 


\section{Federal best practices to restore and recover MTS operations}

One major purpose of this report is to review the impacts, challenges, and successes of the 2017 hurricane season to identify best practices and opportunities to improve resilience. The critical actions summarized below were common across all three storms (Harvey, Irma, and Maria). Note that RIAT member agencies place a high priority on proactive preparation for hurricane events. The emphasis on preparation appears to have played a crucial role in ensuring the poststorm response, and recovery was successful despite the intensity and number of events that occurred.

Many of the discussions held during the development of this report defined how those pre-storm actions were adapted to apply to and/or overcome challenges between storms. Consequently, many of the Critical Response and Recovery Actions recommended below actually pertain to pre-storm activities, not only at the beginning of the hurricane season but within the season as agencies captured synergies of lessons learned and available resources generated by one storm were utilized to better respond to the next storm. These critical actions are listed below and can be used as a guide for the future.

\section{Hurricane Season Kick-off Meeting}

Pre-season kick-off meetings are held just before or at the start of hurricane season and are led by the USCG, the area port harbor safety committee, or Area Maritime Security Committee located in COTP zones normally affected by hurricanes. These meetings include both government and nongovernmental organizations and serve to

\section{Best Practices from Hurricane Sandy}

By providing this review of the 2017 season, it is important to note that 2012's Hurricane Sandy resulted in a series of best practices that Federal agencies, state, and local governments have recognized.

State and local governments, federal agencies, and academics have all conducted post-storm assessments of Hurricane Sandy. These assessments identified various best practices such as the need for back-up power sources for ports, relocation of critical electrical infrastructure out of the way of storm surge and saltwater inundation, and greater use of the US Coast Guard MTSRU. For more information on the lessons learned from Hurricane Sandy, please see Appendix C.

With each hurricane posing unique challenges, understanding the capacity of the MTS to respond and recover between disruptions and adapt to future storms establishes a stronger and more resilient MTS.

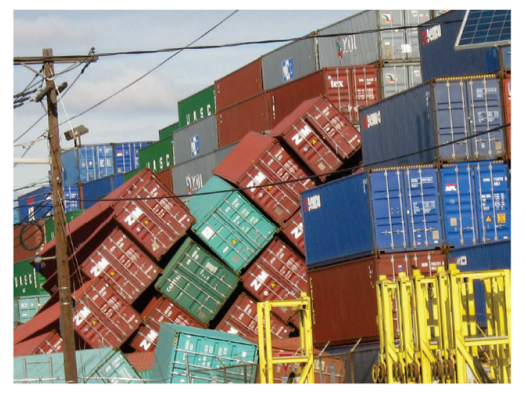


establish relationships between first responder agencies, raise awareness in hurricane preparations, review specific severe weather contingency and security plans, discuss resource and material gaps and needs for responders, and adjust plans when necessary.

\section{Full Scale Hurricane Exercise with Port Coordination Committees}

The RIAT members from USCG reported that full-scale hurricane exercises were conducted as a regular practice across COPT port zones affected by hurricanes. The exercises are run in different (COTP) zones with participation from standing committees that include various federal agencies (USCG, NOAA, EPA, FEMA, etc.), local and state emergency management, port associations and administrations, local and state government, and industry partners. The goals of these exercises are to raise awareness about, prepare for, and review contingency plans for future storms. Other important goals are to identify key roles in preparation, response, and recovery as well as to inform MTSRU on necessary updates or adaptations, and to address gaps in support.

\section{Pre-storm Port Assessments}

The USCG works with deep-draft vessel owner/operators or designated representatives and regulated port facilities to identify each vessel or facility's intentions for operations leading up to, during, and after each storm (e.g., departing port, submission and approval of heavy weather mooring plans if staying, securing crane operations, securing facility). The USCG also pre-designates marine safety response and port recovery personnel with resources ready to respond post-storm for port assessments. Port assessment or emergency action teams are set up to respond from port facility to port facility to identify damages, flooding, security vulnerabilities, and various other storm impacts.

\section{Interagency Efforts for Navigation Channel Reopening}

Several agencies identified navigation channel surveys, channel clearing, and dredging as extremely critical (if not the most important) set of actions leading to the reopening of ports and restoration of the MTS. For example, Hurricane Harvey caused significant damages and extreme shoaling to the Houston Ship Channel and surrounding navigation waterways; therefore, a collaborative and widespread surveying effort was necessary to determine and identify the extent of damages. The Texas Joint Hurricane Response Team enabled the USCG, NOAA, and USACE to 
coordinate information derived from initial surveys of the federal waterways to inform USCG COTP decisions to reopen areas within the port and determine necessary restrictions (e.g., minimum draft, daylight hours only). Parallel operations of the Port Coordination Team effectively prioritized movements within the USCG COTP constraints and often informed prioritization of ATON restoration, debris removal, and emergency dredging.

\section{ATON Verification and Resiliency}

ATON pre-planning, verification, damage assessment, and repair and replacement were determined to be critical actions due to the inherent requirement for ATON to reopen operational navigation channels for port access and MTS recovery. USCG buoy tenders as well as spare ATON were pre-positioned in safe areas to deploy post-storm to conduct the mission of verification and repair/replacement of critical ATON. Challenges faced during Hurricane Harvey were due to the resulting excessive road flooding as well as sea condition limitations that caused delays and made it extremely difficult to transport the extra ATON to the needed locations and reinstate ATON within the ports of Texas. Similar challenges were noted for Hurricanes Irma and Maria. To mitigate challenges of replacing physical ATON, the USCG has leveraged the use of its NAIS infrastructure to broadcast AIS-ATON in affected ports. By working with USCG District Waterways Offices, a pre-defined list of AIS-ATON can be identified and turned on in advance of an approaching storm event. AIS-ATON can be utilized by USCG units charged with port recovery to rapidly triage aids to navigation and prioritize repairs.

\section{Clear Lines of Communication}

All storm responses and recovery operations faced challenges related to communications. These challenges prompted and facilitated discussions at multiple levels on how to mitigate and overcome future communications disruptions as well as alleviate the impact on response and recovery. Participants identified several improvisations such as utilizing personal very-high frequency radios or staging a communications center aboard a USCG cutter. Remaining flexible as communication challenges arose within one's own agency and with other agencies was critical and necessary in the response and recovery of each storm. Strong communication networks between USCG and USACE pre- and post-storm was key to navigation channel recovery due to the multitude of factors that 
could impede the process, such as funding, access to dredging equipment or contracts, and prioritization of projects.

\section{Useful information and tools for response and recovery}

Any discussion of best practices must include some of the data sources that provide information to make decisions. The MTS is host to a rich variety of tools and datasets for planning and decision-making purposes. For emergency response and recovery, the following resources are utilized to provide information, increase transparency across agencies, and assist in the decision-making processes following the 2017 hurricane season.

\section{USCG - CART}

USCG identified pre-storm status of Essential Elements of Information (EEI) to include waterways and navigation systems, port-area critical infrastructure, port-area vessels, offshore energy, and monitoring systems throughout all COTP zones to aid in identifying clear impacts post-storm via the USCG CART. The CART is updated several times daily throughout the response and recovery phases of the storm to make information available on the status of all EEI and ultimately the port status as a whole.

\section{NOAA Information Resources}

In addition to the dissemination of regular electronic navigation charts, NOAA provided pre-storm aerial imaging that was crucial in supporting the flood and damage assessment of the MTS, as a means to determine a baseline of normalcy. Additionally, NOAA provided assignment of Scientific Support Coordinators (SSCs). The SSCs are set up to address chemical and oil pollution within the ports and operate as a substantial resource to the USCG for identifying pollutant risks and migration in helping to determine impacts in addition to coordinating removal and cleanup efforts.

\section{Homeland Security Information Network (HSIN)}

HSIN is the network for homeland security mission operations that share sensitive but unclassified information among federal, state, local, territorial, tribal, international, and private sector partners. HSIN was a reliable resource during the 2017 hurricane season and was utilized as a means of sharing unclassified information among federal, state, and local partners. The intent of HSIN is to have a central location to manage operations, share data, and provide an alternative means of 
communications via alerts or notices during an event such as hurricane response and recovery.

\begin{abstract}
AIS
Available AIS data broadcast in near real-time from ships within the hurricane-impacted area can provide insights to hurricane response and recovery. These data were queried by the USACE to provide information on the general locations of ships in the Gulf of Mexico during hurricane Harvey, locate lost vessels, and aid in the planning of port operations for interested stakeholders.
\end{abstract}

\title{
Opportunities to enhance response and recovery
}

The aforementioned actions were identified as important for re-establishing MTS operations. Response and recovery actions are fast-paced, chaotic, require flexibility to address unexpected challenges, and present transparency to ensure coordination with private stakeholders. The recommendations in this section are based on improvisation and changes to existing practices that were a direct result of the post-disaster actions taken during the 2017 hurricane season. These actions highlight the difficulty in establishing a uniform prioritization system amongst federal agencies for several response and recovery actions. Examples include when, where, or how to conduct post-storm surveys as well as who or why certain facilities and/or commodities should be assigned a priority to expedite the recovery of a port. For example, after Hurricane Harvey there was limited access to resources and assets to conduct surveys. This made it necessary to examine other options to complete the assigned survey missions. Additionally, when determining prioritization for channel survey needs, commodities critical for adjacent communities or economies must be considered. It is important when considering prioritization to think of the big picture across the MTS including the associated supply chain and potential economic outcomes. Understanding this big picture may require comparing MTS agency standards or protocols for prioritization to make the decision-making process easier and more transparent.

\section{Need for Tools and Protocols for Prioritization at the Regional or National level}

The issue of prioritization arose in all three group discussions as it relates to several topics including directing response and recovery efforts across regions with different agency jurisdictions or districts, queuing vessels for reentry, navigation channel surveys, and space for port operations. 
Protocols exist for the order of response and recovery actions (e.g., USCG vessel reentry priorities are fuel/tanker, Department of Defense assets, perishables, and cruise ships). However, occasionally "one size does not fit all" which requires other factors to be reviewed on a case-by-case basis, meaning no port or geographic region can be considered the same when it comes to prioritization. In practice, prioritization on a single port or small port complex has been met with minimal difficulty. This difficulty increases when considering priorities on regional or national levels. Hence, making sure that priority is scalable based on geographic area impacted is important. Flexible frameworks for prioritization informed by prior discussion on agency jurisdiction and funding helped to mitigate challenges experienced in 2017.

\section{Identify Strategic Locations for Pre-staging of Survey Teams and Equipment}

In response to Hurricane Harvey, the ability to deploy NOAA survey teams with the necessary equipment post-storm was timely but difficult as road flooding limited access to survey vessels. These circumstances prompted more elaborate pre-storm discussions prior to Hurricanes Maria and Irma, and as a result, the survey teams, equipment, and National Defense Reserve Fleet ships were pre-staged more strategically to respond more efficiently for the next storm.

\section{Clear Communications and Evaluation of Port Status vs. Navigation Channel Status}

Evaluating port status and evaluating channel status were two very different tasks. Since Hurricane Harvey created extensive flooding along the Texas coast and Hurricane Maria caused widespread infrastructure damages in the Caribbean, both regions experienced difficulties reopening port facilities even though the navigation channels may have been open with restrictions such as daylight operation or draft limitations. Facility operators had to tackle a myriad of issues - roadside facility access, electricity outages necessary for cranes, cargo handling equipment and lighting, security and operational personnel ability to return to work, dock surveys and dredging, among many other things. These challenges can inhibit a given facility's capability to accept cargo vessels. When the Area Maritime Security Committee (or sub-committees like Port Coordination Committees/Teams) and others are engaged in response and recovery planning and exercises, critical non-port partners should be included to increase insight and coordination across these infrastructure sectors. 


\section{Aid Port Facility Employees in Returning to Work}

Because of road flooding and having to attend to personal response and recovery caused many port facility workers to be absent from work, the ability for port facility workers, security personnel, crane operators, longshoreman, etc., to physically return to work became an unforeseen obstacle in true port recovery. The port and waterway may have been opened, but if the shore-side port workers could not physically return to work, the port had not truly recovered operations.

\section{Recommendations to increase MTS resilience}

Response and recovery actions are important to ensure that critical functions are returned to adequate levels as quickly and efficiently as possible. Compiling best practices ensures that there is a level of improvement between storms but can often be limited to existing laws or regulations. The concept of resilience offers a useful framework to address the ability of the MTS to recover and then purposefully practice change between storm events to be better prepared for future storms. Increased resilience within the MTS will result in a system that is better prepared for future hurricanes and other disruptions (e.g., oil spills, technological failures, shipwrecks, tsunamis). According to Presidential Policy Directive 21, resilience is the ability to prepare for and absorb/withstand, recover from, and adapt between disruptions (The White House 2013). These four concepts are often presented in a cycle that is triggered every time a new disruptive event occurs (Figure 16) (Rosati et al. 2015). This four-step theory is difficult to apply in practice because it requires that equal attention be given to understanding how well the system is prepared, able to resist, recover, and adapt between storms. Adaptation, in particular, is a difficult concept to gauge. Therefore, the RIAT agencies undertook an exercise to identify new actions that not only address restoration and recovery but to suggest improvements in preparation and adaptation practices.

To help accomplish this goal, the RIAT Figure 16. The cycle of resilience. compiled recommendations for actions that increase preparation, response, recovery, and adaptation. These ideas were compiled by RIAT members and representatives from RIAT agencies during a workshop session (held at the DOT in May 2018) where participants were asked to 
rank their ideas according to perceived feasibly and impact. Any actions that were suggested multiple times are highlighted below as recommendations, along with the full list of actions as a graph (Figure 17, Figure 18, and Figure 19).

\section{Preparation action recommendations}

The RIAT identified actions that could increase the resilience of the MTS through preparedness. The following recommendations have been identified as important and have the support of multiple workshop attendees. Figure 17 includes all action suggestions plotted by impact and feasibility. Preparation action recommendations include the following:

- Participate in yearly training and drills to ensure that response and recovery teams and stakeholders are educated with the correct skill sets and credentials.

- Incentivize preparedness by promoting proactive maintenance for infrastructure systems.

- Maintain pre-established contracting mechanisms for emergency response operations.

- Pre-identify staging areas and storage areas for response and recovery equipment, fuel, and supplies.

- Prioritize key infrastructure systems and deliveries for directing response and recovery actions.

- Identify critical infrastructure interdependencies and establish a multiagency data sharing platform with a web-based interface.

Figure 17. Actions to increase preparedness.

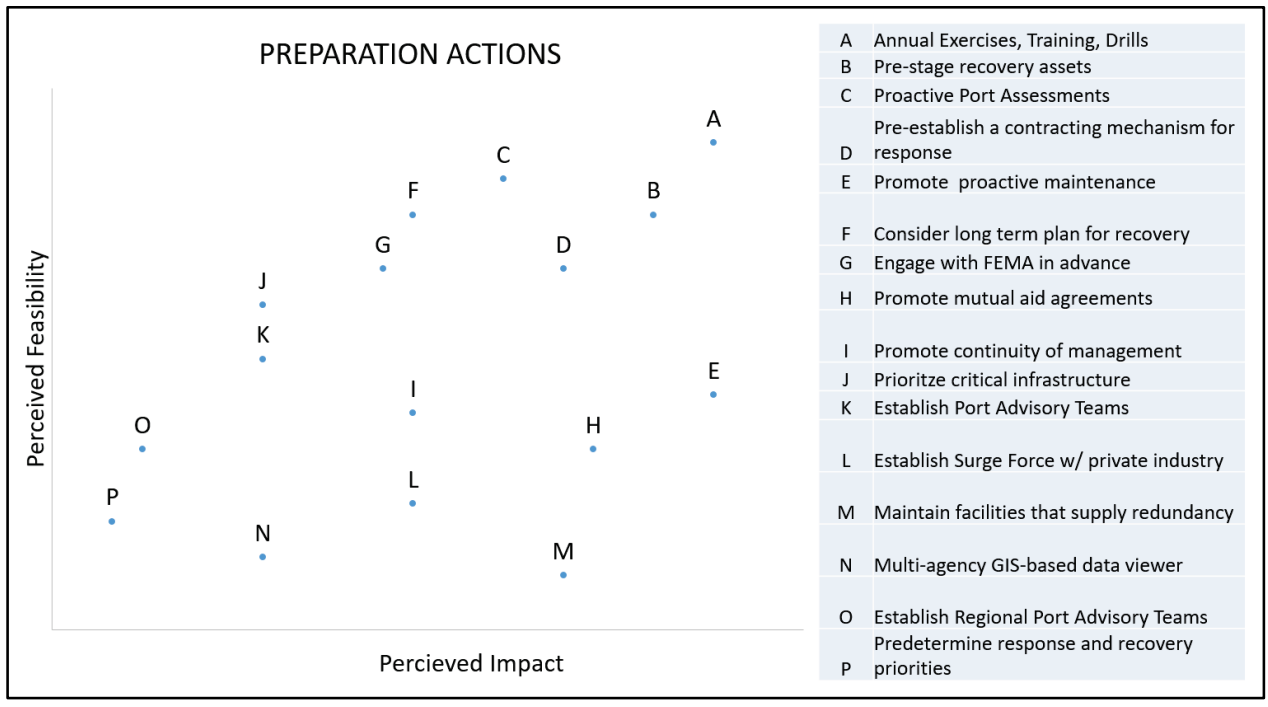




\section{Resist and recovery action recommendations}

The RIAT addressed increasing the ability of the system to resist and recover from disruption. Resist relates to immediate actions to save lives and prevent further damage during an emergency (corresponding to the response phase of emergency management). Recovery is the effort to return the system back to normal (or even better) operation. The following recommendations have been identified as important by the RIAT and multiple members of the workshop. Figure 18 includes all action suggestions plotted by impact and feasibility. Resist and recovery action recommendations include the following:

- Share data across federal agencies for recovery projects through interagency teams and data-sharing platforms that can be shared with state, local, tribal, and territorial governmental coordinating councils and the private sector.

- Deploy MIST kits and NOAA National Response Team members to outfit vessels of opportunity with survey equipment (pilot vessels, barges, monitoring for critical energy services, etc.).

- Utilize surge force and ensure appropriate management continuity.

- Embed MTS experts where necessary - USCG, FEMA field offices, local offices.

- Invest in unmanned autonomous vessel technologies for pre- and poststorm surveys.

Figure 18. Actions to improve resistance and recovery.

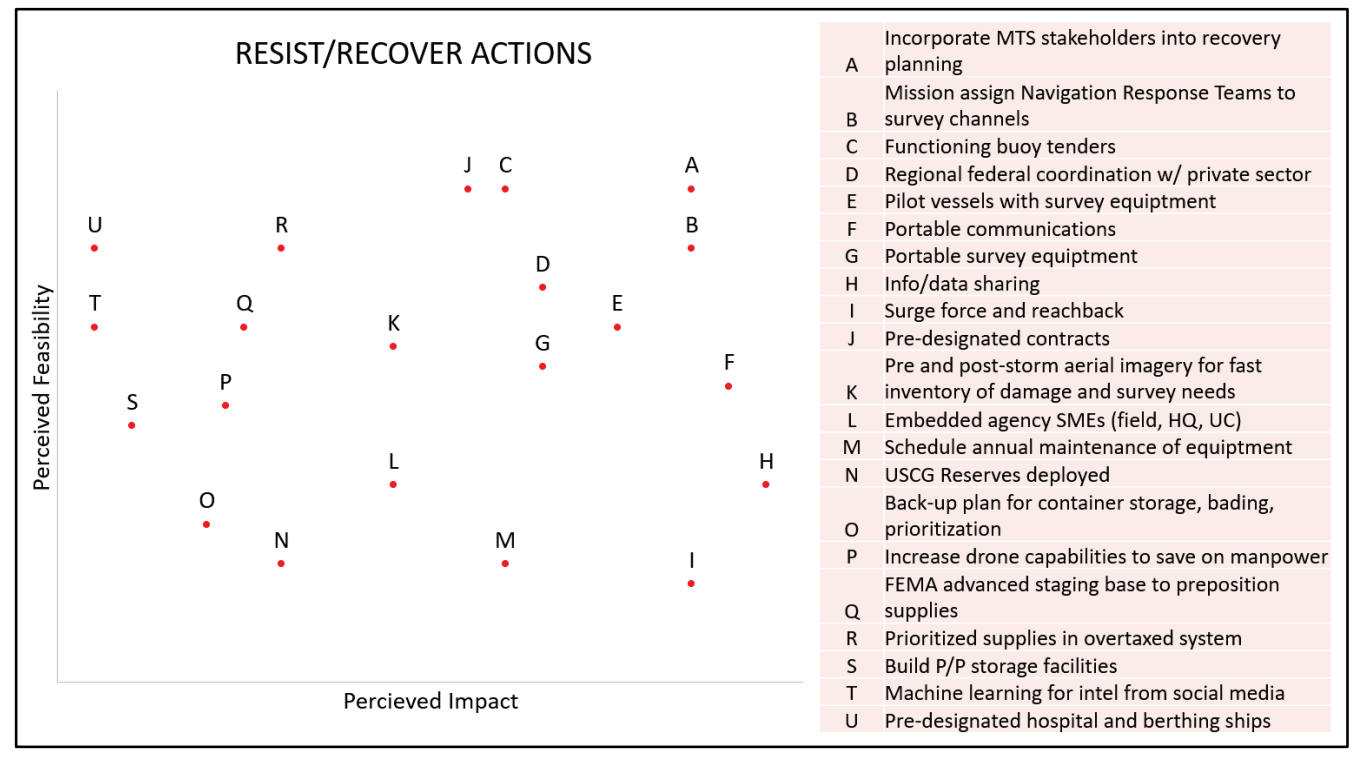




\section{Adaptation action recommendations}

Finally, the RIAT developed a number of actions to adapt between disruptions and increase the resilience of port systems. The RIAT has identified the following recommendations with the support of multiple workshop attendees. Figure 19 includes all action suggestions plotted by impact and feasibility. Adaptation action recommendations include the following:

- Hold interagency operations-related after-action reviews with a demonstrated commitment to communicating and implementing recommendations.

- Develop a common operating picture of the port systems interdependencies and authorities including owners, operators, dependent businesses, and prioritizations and essential land and maritime functions.

- Hold proactive planning scenario exercises and interagency training sessions where recommendations from the past season are communicated and incorporated.

- Hold a CMTS annual workshop to review the hurricane season.

- Ensure CMTS agencies are engaged in the National Disaster Recovery Framework for infrastructure systems so that land and maritime operations are considered in recovery and mitigation plans.

- Promote or consider new cutting-edge technologies to understand infrastructure redundancies and reduce vulnerabilities to multiple hazards and to improve port services or support in times of disruption or failure of operations.

Figure 19. Actions to adapt between disruptions.

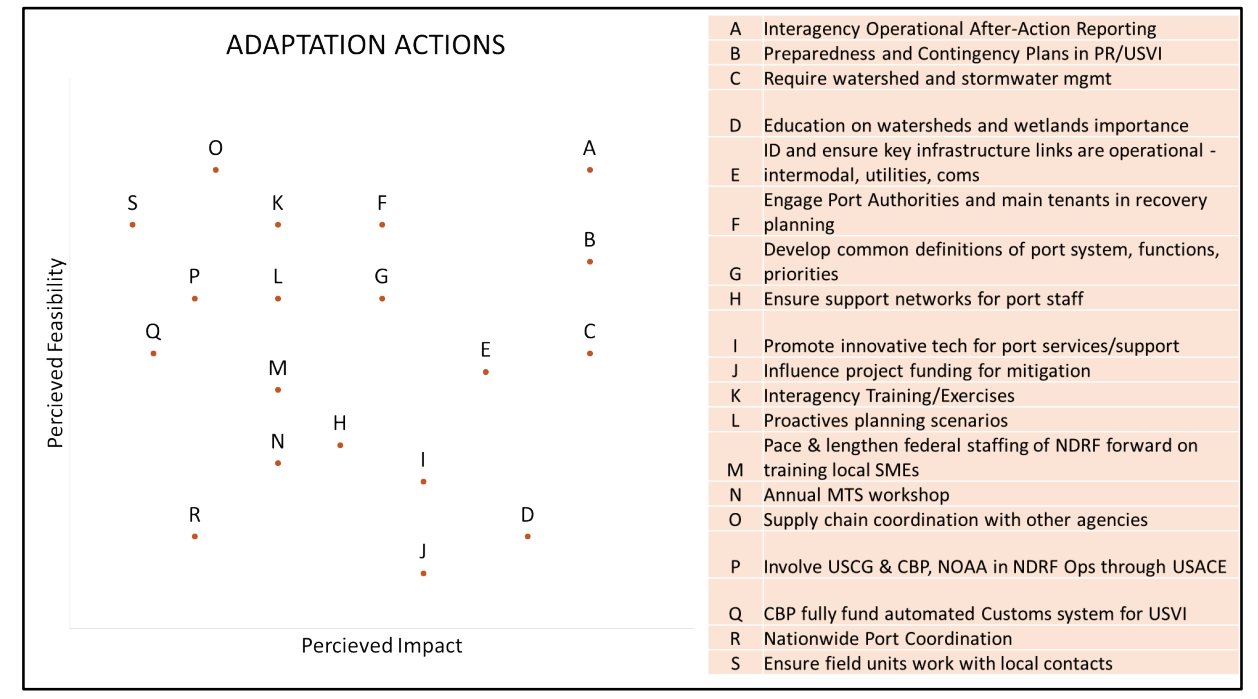




\section{Conclusion}

The 2017 Atlantic hurricane season was one for the record books, with three major hurricanes bringing unprecedented damage and destruction to the Southeast and Gulf Coast regions of the United States and its Caribbean territories. The scope of disruption from Hurricanes Harvey, Irma, and Maria on the MTS was broad, with 45 US ports suspending operations due to weather conditions. However, these closures were relatively short, ranging from several hours to several days. The combined efforts of US federal maritime agencies, in close coordination with state, local, and private sector partners, ensured a rapid resumption of operations that facilitated the flow of commerce and provided a critical lifeline to the affected regions.

A review of federal agency activities to restore MTS operations in response to all three storms revealed several common themes. For pre-storm preparedness, hosting early planning meetings, communication among agencies, centralizing information distribution, and maintaining or updating existing response plans were standout actions. Issues related to telecommunication and the prioritization of ports or other critical infrastructure were experienced by most MTS agencies. Last, the successes shared among agencies included engaging with the private sector to fill gaps in federal response operations, implementing local coordination efforts, and adapting and improving throughout the hurricane season as each storm presented new obstacles to overcome.

Ports and the MTS are critical components of the national economy, facilitating the movement of US goods and services within a global marketplace. They also play a key role in the recovery of the surrounding region after disruption, facilitating the mobilization of response and recovery assets (e.g., Maritime Administration Ready Reserve Fleet) and the delivery of life-sustaining commodities for impacted communities. Implementing the best practices and recommendations identified in this report can help to minimize the impact from future storms and other disruptive events, thus enhancing the resilience of the MTS and surrounding coastal regions. Future storm seasons should include efforts to evaluate the implementation and success of these best practices and recommendations across MTS federal agencies to understand the ability of the MTS to adapt between storms. This, in turn, supports a stronger, more resilient US economy. 


\section{References}

Armour, S., and T. Burton. 2018. "Hospitals Wrestle with Shortage of IV Bags, Linked to Hurricane.” The Wall Street Journal, Dow Jones \& Company, January 7, 2018. www.wsj.com/articles/hospitals-wrestle-with-shortage-of-iv-bags-linked-to-hurricane$\underline{1515349271}$

Blake, E. S., T. B. Kimberlain, R. J. Berg, J. P. Cangialosi, and J. L. Beven II. 2013. Tropical Cyclone Report Hurricane Sandy. (AL182012) 22-29 October 2012. National Hurricane Center. https://www.nhc.noaa.gov/data/tcr/AL182012_Sandy.pdf

Blake, E. S., and D. A. Zelinsky. 2018. National Hurricane Center Tropical Cyclone Report - Hurricane Harvey. (AL092017). https://www.nhc.noaa.gov/data/tcr/AL092017_Harvey.pdf

Bloodgood, P. 2017. "District Works to Overcome Harvey's Impacts to Texas Shipping Industry." US Army Corps of Engineers, Galveston Public Affairs Office. https://www.usace.army.mil/Media/News-Archive/Story-Article-View/Article/1310807/districtworks-to-overcome-harveys-impacts-to-texas-shipping

Brasted, C. 2017. "How Much Rain, Wind, Irma Brought to Florida.” New Orleans and Louisiana Times Picayune. September 11, 2017. https://www.nola.com/hurricane/index.ssf/2017/09/heres_how_much_rain_wind_irma.html

Census Bureau. 2017. "Total US Imports to Puerto Rico, Top 25 6-digit Commodities Based on 2017 Dollar Value." https://www.census.gov/foreigntrade/statistics/state/data/imports/pr.html\#comm

Emergency Support Function Leadership Group. 2015. "Maritime Emergency Response Guide." US Department of Transportation. https://www.transportation.gov/emergency/maritime-emergency-response-guide

FCC (Federal Communications Commission). 2018. “Chairman Pai Proposes \$954 Million Plan for Puerto Rico and USVI.” Statement from the Federal Communications Commission, March 6, 2018. https://www.fcc.gov/document/chairman-pai-proposes-954-million-plan-puerto-rico-and-usvi

FEMA (Federal Emergency Management Administration). 2017a. Historic Disaster Response to Hurricane Harvey in Texas. September 22, 2017. https://www.fema.gov/news-release/2017/09/22/historic-disaster-response-hurricane-harveytexas

FEMA (Federal Emergency Management Administration). 2017b. Progress Update on Hurricanes Irma and Maria in the US Virgin Islands. December 7, 2017. https://www.fema.gov/news-release/2017/12/07/progress-update-hurricanes-irma-and-mariaus-virgin-islands

FEMA (Federal Emergency Management Administration). 2017c. Hurricane Maria Response and Relief Operations Underway. HQ-17-131. September 21, 2017. https://www.fema.gov/news-release/2017/09/21/hurricane-maria-response-and-reliefoperations-underway 
FEMA (Federal Emergency Management Administration). 2018. Robert T. Stafford Disaster Relief and Emergency Assistance Act, as Amended, and Related Authorities as of August 2016. https://www.fema.gov/medialibrary/assets/documents/15271

Ferris, D. 2018. "NATURAL DISASTERS: How Shortages Are Worsening Puerto Rico's Blackout.” E\&E News, Climatewire, February 25, 2018. www.eenews.net/stories/1060074713/

Flood Control and Coastal Emergency Act 33 USC. 701(n) (69 Stat. 186), Flood Control and Coastal Emergency Act (Public Law-84-99). Accessed June 2018. http://www.iwr.usace.army.mil/Portals/70/docs/frmp/PL84-99factsheet.pdf

Florida Ports Council. 2018. "Florida Seaport Fast Facts.” www.flaports.org

Florida Seaports. 2011. An Economic Analysis: Priority Seaport Projects to Expand Capacity, Enhance Competitiveness, Accelerate Economic Growth, and Create Well-Paying Jobs Statewide." Prepared by Martin Associates. http://scdn.flaports.org/wpcontent/uploads/Martin_Associates_Analysis_of_Seaport_Priority_Projects_February_2011.pdf

Henry, D. 2017. "Rising Gas Prices after Harvey Threatens Trump Economy.” The Hill. September 14, 2017. http://thehill.com/policy/energy-environment/348932-rising-gasprices-after-harvey-threaten-trump-economy

HUD (US Department of Housing and Urban Development). 2018. HUD Approves \$616 Million Florida Disaster Recovery Plan. June 28, 2018. https://www.hud.gov/press/press_releases_media_advisories/HUD_No_18_065

NOAA (National Oceanic and Atmospheric Administration). 2016. Describing the Ocean Economies of the US Virgin Islands and Puerto Rico. https://coast.noaa.gov/digitalcoast/training/econ-usvi-pr.html

NOAA (National Oceanic and Atmospheric Administration). 2018. Harvey, Irma, Maria and Nate retired by the World Meteorological Organization, Destructive hurricanes slammed parts of United States, Caribbean in 2017. http://www.noaa.gov/media-release/harvey-irma-maria-and-nate-retired-by-worldmeteorological-organization

NOAA NHC (National Oceanic and Atmospheric Administration, National Hurricane Center). 2017a. Hurricane Harvey Bulletin, Miami Florida August 25, 2017. Corpus Christi, Texas, Weather Forecast Office. https://www.nhc.noaa.gov/archive/2017/al09/al092017.public.023.shtml

NOAA NHC (National Oceanic and Atmospheric Administration, National Hurricane Center). 2017b. Hurricane Irma. https://www.nhc.noaa.gov/archive/2017/al11/al112017.public.046.shtml

NOAA NHC (National Oceanic and Atmospheric Administration, National Hurricane Center). 2018. Costliest US Tropical Cyclones Tables Updated. https://www.nhc.noaa.gov/news/UpdatedCostliest.pdf 
NOAA NOS (National Oceanic and Atmospheric Administration, National Ocean Service). 2018. Hurricanes: Preparedness, Response, Recovery. Accessed June 2018. https://oceanservice.noaa.gov/hazards/hurricanes/\#response

NOAA NOS (National Oceanic and Atmospheric Administration, National Ocean Service). 2008. Supporting Marine Transportation. https://oceanservice.noaa.gov/annualreport/marine.html

NOAA NOS (National Oceanic and Atmospheric Administration, National Ocean Service). 2018. Hurricane Irma NOS Fiscal Year 2017 Year in Review. https://oceanservice.noaa.gov/annualreport17/hurricane-irma.html

NOAA NWS (National Oceanic and Atmospheric Administration, National Weather Service). 2017. Hurricane Harvey and Its Impacts on Southeast Texas from August 25th to 29th, 2017. Houston/Galveston, Texas Weather Forecast Office. http://www.weather.gov/hgx/hurricaneharvey

NOAA OCM (National Oceanic and Atmospheric Administration, Office of Coastal Management). 2018. Fast Facts - Hurricane Costs. https://coast.noaa.gov/states/fast-facts/hurricane-costs.html

Pérez, M. C., A. D. Marrero, and L. A. Rivera. 2017. External Trade Statistics Puerto Rico 2016. Government of Puerto Rico, Office of the Governor Planning Board. http://jp.pr.gov/Portals/0/Economia/Comercio\%20Exterior/External\%20Trade\%20Statistics/et s-2016\%20(v1).pdf?ver=2017-08-23-092107-857

Robert T. Stafford Disaster and Emergency Assistance Act 42 USC. 5121 et seq., Robert T. Stafford Disaster and Emergency Assistance Act (Public Law-93-288 as amended). Accessed June 2018. https://www.fema.gov/media-librarydata/1519395888776-af5f95a1a9237302af7e3fd5b0d07d71/StaffordAct.pdf

Rosati, J. D., K. F. Touzinsky, and W. J. Lillycrop. 2015. "Quantifying coastal system resilience for the US Army Corps of Engineers.” Environment Systems and Decisions 35: 196-208.

Schmider, K. 2010. "Will New Legislation Shatter the Pharma Industry's Tropical Dreams?” Life Science Leader Magazine, December 2010. http://www.lifescienceleader.com/index.php?option=com_jambozine\&layout=article\&view=pag e\&aid $=4152 \&$ Itemid $=56 \& w w p a r a m=1300114300$

Smythe, T. C. 2013. Assessing the Impacts of Hurricane Sandy on the Port of New York and New Jersey's Maritime Responders and Response Infrastructure. Center for Maritime Policy \& Strategy, US Coast Guard Academy.

Steenson, L. 2017. "Salvaging Boats, Protecting the Environment: The Aftermath of Hurricane Maria." Coast Guard Compass, November 28, 2017. Http://www.coastguard.dodlive.mil/2017/11/salvaging-boats-protecting-the-environment/

Texas Department of Transportation. 2017. Ports and Waterways Educational Series. https://ftp.dot.state.tx.us/pub/txdot-info/sla/education_series/ports-waterways.pdf

Texas Port Association. 2015. Economic Impact of the Texas Ports on the State of Texas and the United States. Prepared by Martin Associates for Texas Port Association. Brownsville, TX. www.texasports.org 
The Virgin Islands Consortium. 2017. "Maria Has Arrived to St. Croix with Punishing Winds and Rain; Projected to Last until Wednesday Morning before Moving over to the PR. September 19, 2017. https://viconsortium.com/featured/maria-has-arrived-tost-croix-with-punishing-winds-and-rain-projected-to-last-until-wednesday-morning-beforemoving-over-pr/

The Virgin Island Daily News. 2017. "Port Authority Updates Public on Hurricane Recovery Progress.” November 18, 2017. http://www.virginislandsdailynews.com/news/port-authority-updates-public-on-hurricanerecovery-progress/article_7959d2a5-28d4-5a48-903f-ab72bc84be1f.html

The Weather Channel. 2017. Hurricane Central. "Hurricane Irma Recap.” September 12, 2017. https://weather.com/storms/hurricane/news/hurricane-tropical-storm-irma-recap-2017

The White House. 2013._Presidential Policy Directive 21 - Critical Infrastructure Security and Resilience. February 12, 2013. https://obamawhitehouse.archives.gov/thepress-office/2013/02/12/presidential-policy-directive-critical-infrastructure-security-and-resil

Turner, R., and E. Freiermuth. 2017. Travel and Tourism Economic Impact 2017 US Virgin Islands. World Travel and Tourism Council.https://www.wttc.org//media/files/reports/economic-impact-research/countries-2017/usvirginislands2017.pdf

United States Trade Numbers. 2018. Port of San Juan, Puerto Rico. World City Trade Numbers. Accessed_15 May. https://www.ustradenumbers.com/port/port-of-san-juanpuerto-rico/

USACE (US Army Corps of Engineers). 2018a. 2017 Hurricane Season. http://www.usace.army.mil/Missions/Emergency-Operations/Hurricane-Season/

USACE (US Army Corps of Engineers). 2018b. Hurricane Harvey Response. http://www.usace.army.mil/Hurricane-Harvey-Response/

USACE (US Army Corps of Engineers). 2018c. "USACE Awards Additional \$140.5 Million for Power Grid Restoration Efforts in Puerto Rico.” April 7, 2018. https://www.usace.army.mil/Media/News-Releases/News-Release-ArticleView/Article/1487720/usace-awards-additional-1405-million-for-power-grid-restoration-effortsin-puer/

US Code of Regulations. 33 C.F.R. 165.781(b)(5) Hurricane Port Condition ZULU.

US Code of Regulations. 33 C.F.R. 165.781(b)(2-4) Hurricane Port Conditions Whiskey, $X$-Ray, and Yankee.

US Department of Transportation, Maritime Administration. 2018. National Defense Reserve Fleet and Services. Accessed June 2018. https://www.maritime.dot.gov/national-defense-reserve-fleet/ndrf-fleet-and-services

US Department of Transportation, Maritime Administration. 2017. Maritime Administration Mobilizes National Defense Reserve Fleet Vessels in Support of Hurricane Harvey. September 1, 2017. https://www.transportation.gov/briefingroom/marad0517 
US DOL BLS (US Department of Labor, Bureau of Labor Statistics). 2011. The Pharmaceutical Industry: An Overview of CPI, PPI, and IPP, The Special Case of Puerto Rico. October 2011. https://www.bls.gov/ppi/pharmpricescomparison.pdf

US DOL BLS (US Department of Labor, Bureau of Labor Statistics). 2018. Puerto Rico Price Movements Top Exports and Other Highlights. April 2018. https://www.bls.gov/mxp/puertorico.pdf

US DOT BTS (US Department of Transportation, Bureau of Transportation Statistics). 2017. Freight Facts and Figures 2017. Chapter 2 "Freight Moves in Domestic and International Trade." https://www.bts.gov/bts-publications/freight-facts-andfigures/freight-facts-figures-2017-chapter-2-freight-moved

US DOT OST (US Department of Transportation, Office of the Secretary of Transportation). 2016. Lessons Learned from Super Storm Sandy. UTC Spotlight, No. 104, November. https://www.transportation.gov/sites/dot.gov/files/docs/spotlight_1116.pdf

US EIA (US Energy Information Administration). 2017. "Hurricane Harvey Caused US Gulf Coast Refinery Runs to Drop, Gasoline Prices to Rise." Today in Energy, 11 September 2017. https://www.eia.gov/todayinenergy/detail.php?id=32852

US EIA (US Energy Information Administration). 2018. Texas State Profile and Energy Estimates. https://www.eia.gov/state/?sid=TX

US EPA (US Environmental Protection Agency). 2018. EPA's Role in Emergency Response. https://www.epa.gov/emergency-response/epas-role-emergency-response

US House Transportation \& Infrastructure Committee. 2017. “Opening Statement." Emergency Response and Recovery: Central Takeaways form the Unprecedented 2017 Hurricane Season Hearing. November 2, 2017. https://transportation.house.gov/calendar/eventsingle.aspx?EventID=402001

US Virgin Islands Bureau of Economic Research. 2017. Cruise Passenger Arrivals - US Virgin Islands Year to Date, Monthly, Quarterly, and Annual Totals January 2016 to June 2017. http://www.usviber.org/wp content/uploads/2016/11/CP17-june.pdf

Workboat. 2017. "Training Ships Bound for Puerto Rico Hurricane Relief." Workboat. September 27, 2017. https://www.workboat.com/news/government/training-ships-boundpuerto-rico/ 


\section{Appendix A: Agencies and Offices of Workshop Attendees}

US Army Corps of Engineers

Institute for Water Resources

Engineer Research and Development Center

Engineering and Construction Division, Headquarters

US Coast Guard

District Eight New Orleans: Enforcement Branch

District Seven Miami

Sector Mobile

Sector Miami: Contingency Planning

Headquarters: Port Resiliency/Recovery

Headquarters: Office of Port \& Facility Compliance

USCG FEMA Liaison

US Committee on the Marine Transportation

US Department of Homeland Security

National Protection and Programs Directorate - Office of Infrastructure Protection

US Department of Transportation

Office of the Secretary of Transportation

Bureau of Transportation Statistics

US Maritime Administration

Office of Ports and Waterways Planning

US National Oceanic and Atmospheric Administration

Office of Coast Survey

Office for Coastal Management

Office of Response and Restoration

Navy

Oceanographer of the Navy 


\section{Appendix B: Interdependencies with Non- Federal Systems and Organizations}

The marine transportation system operates as a system within systems, and no actions or recommendations undertaken by federal agencies to improve resilience will be effective unless understood and supported by the stakeholders and sectors that utilize or support the MTS. In this section, several of the non-federal infrastructure systems, stakeholders, and organizations that rely on or support the MTS are highlighted.

\begin{tabular}{|c|c|}
\hline Energy Sector & $\begin{array}{l}\text { The delivery of products and transport via road, rail, or } \\
\text { pipeline to maintain national supply needs. As an example, } \\
\text { the Port of Houston handles the import of crude oil for } \\
\text { national distribution to oil refineries. Closure of the Port } \\
\text { places a roadblock on the supply chain, which can result in } \\
\text { supply complications on the national level. Additionally, many } \\
\text { of the ports in Florida handle the import of gas and diesel } \\
\text { that fuel the state. The closure of key ports can result in } \\
\text { parts of the state running out of product. }\end{array}$ \\
\hline Electricity Supply & $\begin{array}{l}\text { After Hurricane Harvey, the recovery of ports was dependent } \\
\text { on the quick return of necessary electricity supplies to critical } \\
\text { infrastructure such as hospitals and port-based refineries. }\end{array}$ \\
\hline Travel and Tourism & $\begin{array}{l}\text { The operation of cruise ships at sea can result in the rise of } \\
\text { potential political issues that requires the early off-loading of } \\
\text { passengers when the MTS is subject to possible disruptions. } \\
\text { Important to off load early. }\end{array}$ \\
\hline Supply Chain Issues & $\begin{array}{l}\text { Many national and local industries are dependent on the } \\
\text { import and export of products through ports such as } \\
\text { agriculture (grain, stock, etc.), retail, food and water, } \\
\text { medicine (products and materials), and heavy industrial } \\
\text { equipment. }\end{array}$ \\
\hline $\begin{array}{l}\text { Local Port } \\
\text { Stakeholders }\end{array}$ & $\begin{array}{l}\text { Port Associations, pilot authorities, sector specific agents, } \\
\text { USCG COPT, Port Coordination Team, and state and local } \\
\text { maritime agencies. }\end{array}$ \\
\hline $\begin{array}{l}\text { Surface } \\
\text { transportation }\end{array}$ & $\begin{array}{l}\text { Ensuring drivers are available to transport goods into and out } \\
\text { of ports; intermodal connections; port networks to divert flow } \\
\text { of materials; and brokers to negotiate rerouting with } \\
\text { commercial operators. }\end{array}$ \\
\hline $\begin{array}{l}\text { Communication and } \\
\text { Information } \\
\text { Technology }\end{array}$ & $\begin{array}{l}\text { Internal and external port communications and automated } \\
\text { operations performance requirements. }\end{array}$ \\
\hline
\end{tabular}




\begin{tabular}{|l|l|}
\hline Labor & $\begin{array}{l}\text { External operators and personnel - the successful operation } \\
\text { of a port is dependent on employees that can be external to } \\
\text { the port including bridge operators, labor unions (e.g., } \\
\text { longshoremen and crane operators), salvage operators, pilot } \\
\text { associations, and the towboat industry. For many ports, the } \\
\text { local pilots association and towboat industry provide } \\
\text { necessary support for day-to-day operations of ports. }\end{array}$ \\
\hline
\end{tabular}

The recovery of the MTS depends on non-federal organizations and private industry to return the system to normal operations. The following non-federal organizations play key roles in recovery operations.

\begin{tabular}{|c|c|}
\hline $\begin{array}{l}\text { Local and State } \\
\text { Government }\end{array}$ & $\begin{array}{l}\text { In Florida, after Hurricane Irma, local counties coordinated to } \\
\text { provide MTS responders refueling stations across the state } \\
\text { to facilitate the transportation of survey vessels. Local law } \\
\text { enforcement offices also provided port security during and } \\
\text { after storms to permit the port to accept vessels during } \\
\text { recovery operations. Additionally, states utilized Emergency } \\
\text { Operation Center to facilitate federal operation in state such } \\
\text { as coordinating with the FEMA compliance requirements. }\end{array}$ \\
\hline Pilots Associations & $\begin{array}{l}\text { Pilots association: assisted with debris in waterways through } \\
\text { the use of vessels of opportunity, (i.e., a volunteered local, } \\
\text { commercial, or recreational vessel). }\end{array}$ \\
\hline Towboat Industry & $\begin{array}{l}\text { Towboat industry: utilized vessels of opportunity to conduct } \\
\text { surveys and debris assessments. These surveys accelerated } \\
\text { the reopening of entire waterways. }\end{array}$ \\
\hline Maritime Industry & $\begin{array}{l}\text { Tugboats, offshore supply vessels, cruise ships, and school } \\
\text { ships all provided various levels of support to open ports and } \\
\text { waterways, provide fuel, evacuate people, and provide } \\
\text { berthing for victims and responders. }\end{array}$ \\
\hline $\begin{array}{l}\text { Construction } \\
\text { Industry }\end{array}$ & $\begin{array}{l}\text { Provided assistance with debris removal, reconstruction of } \\
\text { MTS infrastructure, and dredging or salvage needs. }\end{array}$ \\
\hline $\begin{array}{l}\text { Local Economic } \\
\text { Development } \\
\text { Chapters }\end{array}$ & $\begin{array}{l}\text { Local Chambers of Commerce provided support and } \\
\text { motivation to return the MTS to normal operation to facilitate } \\
\text { the return to normal business operations and the inflow of } \\
\text { economic operations. These groups also advocated for the } \\
\text { return of tourism and the reopening of small businesses. }\end{array}$ \\
\hline Local utilities & $\begin{array}{l}\text { Power companies, maritime industry, tourism, commercial } \\
\text { activities, security industries. }\end{array}$ \\
\hline $\begin{array}{l}\text { Non-governmental } \\
\text { Relief Organizations }\end{array}$ & $\begin{array}{l}\text { For example, American Red Cross, Samaritan's Purse, } \\
\text { Catholic Relief Services. }\end{array}$ \\
\hline
\end{tabular}




\begin{tabular}{|l|l|}
\hline $\begin{array}{l}\text { Communications } \\
\text { Industry }\end{array}$ & $\begin{array}{l}\text { The recovery of cell towers, internet, and phone lines to } \\
\text { returned communication capabilities to MTS operators. } \\
\text { Social media also played a role in restoring operations as } \\
\text { private platforms were utilized while recovery of normal } \\
\text { operations were underway. }\end{array}$ \\
\hline $\begin{array}{l}\text { Local USCG Marine } \\
\text { Transportation } \\
\text { System Recovery } \\
\text { Units }\end{array}$ & $\begin{array}{l}\text { Coordinated information across states and counties, } \\
\text { parishes and state EOCs, public affairs - joint information } \\
\text { centers. }\end{array}$ \\
\hline $\begin{array}{l}\text { National and Local } \\
\text { Media }\end{array}$ & Communicated information to increase public safety. \\
\hline Dredging Industry & $\begin{array}{l}\text { Key actors for the operation of the MTS by executing } \\
\text { authorized contracting agreements. }\end{array}$ \\
\hline Tourism Industry & $\begin{array}{l}\text { Cruise ships were immediately offloaded, cruise industry } \\
\text { invested in beach and environmental cleanup and } \\
\text { accelerated recovery because of long-term interest in } \\
\text { preserving recreation opportunities. }\end{array}$ \\
\hline
\end{tabular}




\section{Appendix C: Learning from Previous Storms - Challenges and Lessons Learned from Hurricane Sandy}

When Hurricane Sandy made landfall in New Jersey on October 29, 2012, it marked the beginning of a dramatic change to the region's approach to preparing for and responding to hurricane impacts. Lessons learned from Hurricane Sandy were well documented through studies and workshops, and the MTS community began to think about consequences of events in areas that were previously not considered at risk. Six years later, Hurricane Harvey struck the Texas coast, and many major news networks and sources published articles directly referencing what lessons were learned from Sandy, and how coastal communities - including ports and the MTS - had adapted their operations to better handle major hurricane impacts (Figure 20). Before providing a review of the 2017 season, it is important to understand what lessons were learned during Sandy to contextualize the findings. While each hurricane is unique in its challenges and drivers, understanding the capacity of the MTS to adapt between disruptions and the impacts of acting on lessons learned from the past can provide a foundation for continuing to review each hurricane season and highlight areas for improvement.

Figure 20. Major news headlines referred to lessons learned from Hurricane Sandy in the wake of Harvey, Irma, and Maria.

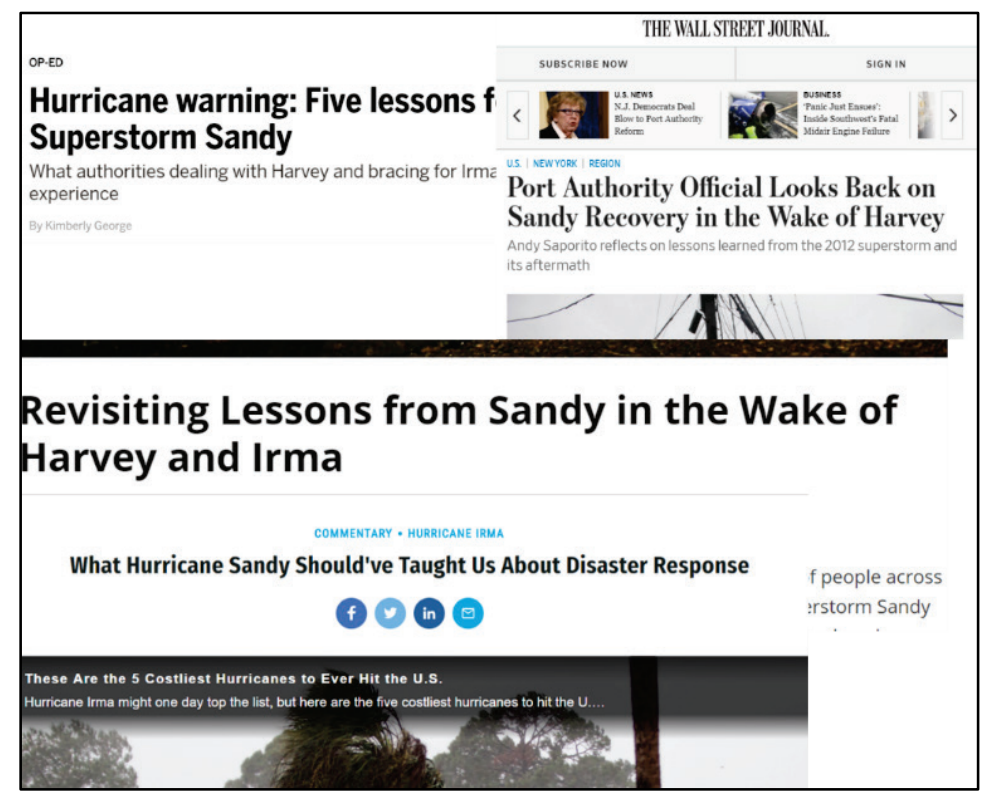


Prior to Hurricane Sandy, the Northeast region had experienced hurricanes Floyd (1999), Isabel (2008), and Irene (2011), all of which caused extensive flooding but minor damage overall to the infrastructure that supported the MTS such as facilities and major waterways. Hurricane Sandy made landfall as a post tropical cyclone with $70 \mathrm{~km}$ maximum sustained winds, but because of its size, Sandy caused "catastrophic storm surge" along the coastlines of New York, New Jersey, and Connecticut (Blake et al. 2013). The resulting storm surge and wave action flooded ports, utilities, and tunnels leading to power outages and limited transportation routes. Waves and storm surge further caused damage to ancillary structures, equipment, and cargo throughout the Port of New York and New Jersey (the Port) itself (US DOT OST 2016). These impacts forced the port to close for 1 week and made returning the Port to normal operation an incredibly difficult logistical challenge. However, the impacts to the Port identified a need to include storm surge planning or consideration in the Port's hurricane plan. During Hurricane Sandy, the USCG closed all of the Port of New York and New Jersey before the storm made landfall on October 28, 2012, and did not fully reopen the port until November 4, 2012, to vessel traffic (US DOT OST 2016; Smythe 2013).

The loss of power at the Port after the storm caused prolonged disruptions to many port activities and facilities and had a snowball effect on its recovery. On November 1, 2012, the Port partially reopened, but because parts of the Port still lacked power to operate the container and oil terminals, the Port could not resume full operation at the same time as the waterways were cleared for operation (Smythe 2013). This meant that even though vessels could return to the Port, the terminals were unable to receive products. Further, without power the Port was dependent on personnel's personal devices (cell phones, laptops, etc.) because services such as landlines, phone towers, and the internet were unavailable (Smythe 2013). These electrical difficulties suggest an opportunity to prioritize greater pre-storm communication and coordination with electrical companies to return power to the Port sooner after a hurricane.

Electrical design was another element of the problems the Port experienced after Hurricane Sandy. Storm surge, saltwater intrusion, and other types of damage impacted the Port's electrical infrastructure, further exacerbating the loss of power. Equipment and infrastructure stored on the first floors or in the basements of waterfront buildings were destroyed. This meant that some alternative power sources, such as backup 
generators or electric engines to power cargo cranes, were unable to operate as expected. Changing design standards to elevate waterfront electrical infrastructure would provide greater protection from future flooding events and possibly prevent extending port closures.

Following a significant port disruption, federal, state, and local authorities look to the USCG MTSRU for guidance when engaging in response and recovery efforts. The MTSRU focuses on reopening a port so that commercial activity can resume as quickly and safely as possible. Prior to Sandy, the Port had only implemented an MSTRU on two prior occasions for hurricanes. Applied here, the MTSRU sets out an arrangement for post-storm survey work of the waterways through a combined publicprivate initiative to conduct surveys necessary to reopen the port (Smythe 2013). The need for communication extended beyond the public sector for emergency response and recovery actions after Sandy. Providing the public, politicians, public officials, and other members of government with information about the Port's recovery proved to be no easy task. As the Port and supporting agencies (NOAA, USACE, and USCG) sought to bring the Port and supporting waterways back to operational capacity, Port representatives needed to educate the greater community on how the port operated, how the MTS worked, and why the supply chain was impacted by the delays in opening (Smythe 2013). To better serve the community at large, the public and its leaders need more comprehensive education on the Port itself, its supporting infrastructure, and the recovery process for MTS.

The prior experiences of recovery participants and the Port community overall also aided the effective coordination, response, and recovery operations after Sandy (Smythe 2013). Two prior disruptions, the 9/11 terrorist attacks and Hurricane Irene in 2011, provided unfortunate opportunities to apply response and recovery actions prior to Hurricane Sandy. This prior experience offered a foundation for responders, port operators, and members of the port community to build on and were key to the recovery operations at the Port and its reopening.

In the almost 6 years since Hurricane Sandy battered the East Coast, government agencies, like the USCG, and academic researchers have identified various successes and challenges as lessons learned to facilitate preparation, recovery, and adaptation actions to extreme coastal weather events. A 2013 USCG study highlighted the lessons described above as areas for possible prioritization for future planning and capacity building 
(Smythe 2013). The successes included internal port coordination, building on prior emergency response experiences, and the utilization of external resources. The challenges identified in no particular order, highlighted the impacts of storm surge, power and electrical infrastructure, and the sharing of available information within the port itself and the public. In examining the 2017 hurricane season, these lessons previously identified can be used to gauge the progress agencies and responders have made in the years following Sandy. 


\section{Appendix D: Marine Transportation System (MTS) Agency Response and Recovery}

The following responses are summarized from both the House Transportation and Infrastructure Committee's Hearing and a roundtable discussion from MTS Resilience Integrated Action Team agencies that were asked to discuss the general response and recovery efforts for the hurricane season at large. Most responses focused on the three largest hurricanes - Harvey, Irma, and Maria. Additional information on federal agency response and recovery activities was provided through the Emergency Support Function Leadership Group's 2015 report Maritime Emergency Response Guide and agency websites.

\section{US Army Corps of Engineers (USACE)}

The USACE, as a member of the federal government's unified national response to disasters and emergencies, directs hundreds of people to respond to disasters all around the world (USACE 2018a). On a national level, USACE assists response and recovery operations undertaken and initiated by the Department of Homeland Security (DHS) and the FEMA. USACE is also the designated lead agency under the National Recovery Support Framework for leading the Infrastructure Systems recovery function with support from the CISA. Specifically, USACE has the responsibility to maintain and ensure the operational status of federal navigation channels at their authorized and appropriate depth post-coastal disturbances (Emergency Support Function Leadership Group 2015). The operation and maintenance of authorized navigation projects, such as locks, dams, port turning basins, and coastal structures, also falls under the responsibility of USACE. Last, USACE works in close coordination with the USCG to facilitate the removal of marine debris that poses an obstruction to vessels transiting through federal navigation channels (Emergency Support Function Leadership Group 2015).

In the aftermath of a coastal disturbance or stressor that impacts waterways and ports, the USACE provides these same services but on a more rapid timescale. During the 2017 hurricane season, two statutes provided the USACE the authority for recovery operations - the Robert $T$. Stafford Disaster and Emergency Assistance Act (Public Law 93-288, as 
amended) and the Flood Control and Coastal Emergency Act (Public Law84-99). Under the Stafford Act, the USACE supports DHS and FEMA operations to carry out the National Response Plan to provide coordinated relief and recovery operations after a disaster (USACE 2018b). The Flood Control and Coastal Emergency Act authorizes the Chief of Engineers to undertake activities including disaster preparedness, advance measures, emergency operations, rehabilitation of flood control works, protection or repair of federally authorized shore protective works, and provisions of emergency water (US Code of Regulations 33 USC. 701(n) (69 Stat. 186)).

The USACE also utilized pre-awarded contracts to assist with response and recovery phases of operation such as debris removal, temporary roofing, distribution of commodities, and generator installation (USACE 2018a). Additional activity undertaken during the 2017 season included the following.

- Executing FEMA-assigned recovery missions in the central Texas coastal area by the USACE Galveston District, which included flood mitigation and reservoir operations, temporary emergency power, debris technical assistance, navigation restoration, temporary housing, infrastructure assessments, and commodities technical assistance.

- Tracking the timeline and milestones for Hurricane Harvey which provided an opportunity to offer lessons learned on performance during preparation and response.

- In Puerto Rico, Operation Blue Roof installed more than 30,000 temporary roofs; Temporary Power set a new record with more than 1,200 generator installations; and the Debris Management Mission has collected more than 1.8 million yd 3 of debris.

- Puerto Rico presented a major logistical challenge in getting personnel, emergency commodities, and materials for rebuilding on the island. The USACE was charged with the mission to restore the power grid, and to do this, the agency relied almost exclusively on the use of Crowley Barge Company to get electrical grid supplies to the island.

\section{US Environmental Protection Agency (EPA)}

The US EPA Office of Emergency Management responds quickly to environmental concerns and natural disasters to rapidly assess and monitor risks such as leaks, spills, air pollutant releases, drinking water contaminations, wastewater, and superfund sites (EPA 2018). The EPA response and recovery activities aid in promoting health and safety by 
ending and cleaning these leaks, restoring services, and providing advice and outreach during the recovery phase for issues like pests, pesticides, indoor air quality, drinking water safety, etc. The EPA also issues temporary, emergency waivers to facilities in the fuel production and distribution system to minimize disruptions to fuel supply.

EPA provides support through requests or when the response capabilities of state and local first responders have been exceeded (EPA 2018). During the 2017 hurricane season, EPA supported numerous activities in the following ways to aid federal response and recovery operations, which included the following:

- Committing more than 375 personnel to help communities in Puerto Rico and the USVI.

- Support the USCG on the recovery of submerged and damaged vessels.

- In Florida, 214 assessments were completed for hazardous material and/or oil-related issues.

- Harvey affected approximately 2,238 drinking water systems; the EPA worked to assess and gather information on drinking water status. In the Virgin Islands, the EPA conducted 1,400 drinking water assessments and aided the 200 communities that depend on drinking water from wells and pumps.

- For Harvey, Irma and Maria, the EPA signed multiple No Action Assurance waivers to address fuel shortages and ease stipulations of fuel types used for generators and response vehicles can be distributed and utilized.

\section{US Coast Guard (USCG)}

The USCG is the responsible agency for addressing MTS recovery efforts in the wake of any hazard that adversely impacts the MTS. Coordination of recovery is facilitated through the local USCG COTP, MTSRU as well as FEMA Emergency Support Functions.

In the event of MTS disruption, the USCG stands up an Incident Command System and MTSRU with either an Incident Command or Unified Command under the Planning section, to enable and facilitate the response and recovery of associated ports. The MTSRU supports the response efforts of the Incident Command and coordinates recovery efforts among the Coast Guard, federal and state/local agencies and organizations. Support functions include tracking and reporting the status 
of the MTS through Essential Elements of Information using the CART, understanding critical recovery pathways, recommending courses of action, providing avenues for various stakeholder input, and providing the Incident Commander/Unified Command with recommended priorities.

The MTSRU is primarily staffed by USCG/federal government personnel and augmented by local maritime expertise. MTSRU personnel are typically tasked pos -storm with determining prioritization of repairs to ATON, development of maritime traffic schemes for safe vessel movement, vessel tracking and cargo movements, advising agencies on how to deploy personnel and resources to facilitate commerce, coordinating salvage, prioritizing channel surveys/debris removal for safe navigation, and any other related efforts to resume port operations. In determining prioritization and making recommendations to appropriate agencies or the Incident Command or Unified Command, the MTSRU is responsible for coordinating and consulting with stakeholders to solicit valuable feedback from impacted industries to help identify ATON, dredging and vessel queue needs as well as tracking recovery issues with the potential to incur long-term recovery issues.

New advances in technology have led the USCG to utilize the NAIS in broadcasting synthetic ATON known as AIS-ATON. The USCG has been working to identify critical AIS-ATON to be turned on in advance of a hurricane. These AIS-ATON lead to faster reconstitution of ports and waterways as units are able to identify discrepant ATON quickly. In addition, deployable AIS-ATON kits allow for the capability to transmit synthetic aids in the absence of NAIS infrastructure.

\section{Department of Homeland Security Cybersecurity and Infrastructure Security Agency (CISA)}

The CISA leads and coordinates national programs and policies on critical infrastructure security and resilience and has established strong partnerships across all levels of government and the private sector. The CISA Infrastructure Development and Recovery (IDR) program within the Protective Security Coordination Division facilitates the CISA responsibilities under the National Disaster Recovery Framework to support the FEMA, the USACE, and local communities in recovering infrastructure operations and systems. IDR deployed trained personnel to disaster-affected areas to steer recovery and rebuilding decisions that 
place heavy emphasis on considerations for enhancing long-term resilience by building back better than before to reduce future costs and vulnerabilities across interdependent sectors and facilities. Overall, CISA has responded to all 2017 disasters, including this year's wildfires.

CISA provided support in the following ways throughout the 2017 Hurricane season:

- CISA IDR deployed professionals to Texas, Florida, Puerto Rico, and the USVI to work with the USACE to develop the recovery support strategies, using its interagency knowledge to leverage networks of partnerships to facilitate information sharing, collaboration, and coordination throughout all phases of the disaster. CISA leads this effort in Texas. All disasters are local, and the CISA locally based Protective Security Advisors and Chemical Security Inspectors provided insights into infrastructure and other preparedness issues in the affected area such as the effects of Harvey on the chemical industry or loss of communications in Puerto Rico after Maria shut down industries that produce critical medical supplies across the United States and Canada. With FEMA support, CISA worked with the manufacturing sector and Government of Puerto Rico to prioritize interdependency studies of infrastructure supporting critical manufacturing and communities that could be used to prioritize investments.

- CISA leveraged its experience in infrastructure data collection, assessment, analysis, and private sector engagement to produce insights that to effectively address resilience in rebuilding damaged infrastructure in Puerto Rico.

\section{Federal Emergency Management Agency (FEMA)}

In the event of a major disaster, it is the responsibility of FEMA to coordinate federal agency responses and to ensure the deployment of necessary federal capabilities (US House Transportation and Infrastructure Committee 2017). FEMA support includes financial assistance to state, tribes, and local governments and individuals, and directing any federal agency to provide additional support to protect life and property (US House Transportation and Infrastructure Committee 2017). 
FEMA coordinates the response through statutory authorization and funding for response activities under the Robert T. Stafford Disaster Relief and Emergency Assistance Act (PL 100-707) (the Stafford Act; FEMA 2018). Under the Stafford Act, FEMA as the lead federal agency, provides national level strategic transportation, movement planning, and the tracking of federal partner resources into the disaster impacted area (Emergency Support Function Leadership Group 2015). As an example of how activities are executed, FEMA will authorize the USCG and the USACE to perform dredging activities to expedite response and recovery operations (Emergency Support Function Leadership Group 2015).

During the 2017 hurricane season, FEMA coordinated activities across agencies to provide aid to Texas, Florida, Puerto Rico, and the USVI. In the Caribbean, this included the following:

- Working with the USCG to conduct search and rescue operations in St. Croix; support USACE missions to provide Puerto Rico and the USVI with temporary power, temporary roofing, debris removal/technical assistance, infrastructure assessment, and commodities management expertise; and Coordinate with the US Department of Energy and its partners in response and power restoration efforts for Hurricane Maria (FEMA 2017c).

\section{National Oceanic and Atmospheric Administration (NOAA)}

The NOAA supports the federal response and recovery mission through providing critical data and expertise. Such services provided by the National Ocean Service (NOS) include maritime-specific navigation, observation, and positioning services as well as the building and maintenance of navigational charts (Emergency Support Function Leadership Group 2015; NOAA NOS 2018). To aid emergency response and recovery, NOS maintains mobile navigation response teams that may be pre-positioned and quickly dispatched to conduct hydrographic surveys to aid the recovery of navigation channels by locating obstructions following coastal disturbances and disasters (Emergency Support Function Leadership Group 2015). The NOAA National Geodetic Survey (NGS) also can provide rapid response remote sensing missions to aid emergency response and recovery actions to make damage assessments. 
Emergency managers rely on the timely information provided by NOAA to make decisions regarding the reopening of ports and waterways and the rapid restoration of maritime commerce. Some notable statistics related to MTS response and recovery include the following:

- The NOAA NGS collected 65,000 aerial images covering over 9,000 miles $^{2}$ of coastal areas. These data were made available for dissemination usually within hours of collection and assisted in damage assessment activities to include the identification navigational hazards.

- The NOAA Office of Coast Survey Navigation Response Teams and the Mobile Integrated Response Team conducted emergency hydrographic surveys or provided survey support within in the following ports:

- Hurricane Harvey: Corpus Christi, Galveston, Houston, Seadrift/Matagorda

- Hurricane Irma: Key West, Miami, and Tampa

- Hurricane Maria: 19 port facilities throughout Puerto Rico and the USVI

- The NOAA Office of Response and Restoration (OR\&R) supported the USCG in hazardous materials response efforts. This included providing guidance on marine debris and vessel salvage. OR\&R deployed its Environmental Response Management Application to provide situational awareness in storm impacted areas.

\section{Department of Transportation - Maritime Administration (MARAD)}

The MARAD operates programs promoting the use of waterborne transportation in coordination with other components of the nation's transportation system. Such work involves the movements of ships and vessels, shipbuilding, port and intermodal development, national security, and safety (Emergency Support Function Leadership Group 2015). During national emergencies, MARAD can make available government-owned vessels, equipment, personnel, and the National Defense Reserve Fleet and its component, the Ready Reserve Force (RRF). In utilizing these vessels as command and control platforms, MARAD provides support for communication, berthing, accommodation, and medical support during national emergencies and disturbances (Emergency Support Function Leadership Group 2015). In response to Hurricane Sandy in 2012, MARAD activated one RRF vessel and two National Defense Reserve Fleet (NRDF) training vessels to provide berthing and meal services (DOT MARAD 2017). Similarly, in 2017 MARAD activated two NDRF vessels for a pre-scripted FEMA mission to support relief efforts in Texas following 
Hurricane Harvey (US DOT MARAD 2017). Subject to the availability of federal funds, MARAD can also charter commercial vessels or procure maritime industry resources. Further, MARAD additionally can provide technical assistance and can authorize grants to improve port infrastructure when Congress appropriates relief funding (Emergency Support Function Leadership Group 2015). 


\section{Unit Conversion Factors}

\begin{tabular}{|l|c|l|}
\hline Multiply & By & To Obtain \\
\hline feet & 0.3048 & Meters \\
\hline gallons (US liquid) & $3.785412 \mathrm{E}-03$ & cubic meters \\
\hline Inches & 0.0254 & Meters \\
\hline miles (US statute) & $1,609.347$ & Meters \\
\hline tons (2,000 pounds, mass) & 1.2023 & Metric tons \\
\hline yards & 0.9144 & meters \\
\hline
\end{tabular}




\section{Acronyms and Abbreviations}

\begin{tabular}{|c|c|}
\hline $\mathrm{AC}$ & Area Committee \\
\hline AIS & Automatic Identification System \\
\hline AIS-ATON & electronic aids to navigation \\
\hline ATON & aids to navigation \\
\hline CART & Common Assessment and Reporting Tool \\
\hline $\mathrm{CB}$ & Coordinating Board \\
\hline CISA & Cybersecurity and Infrastructure Security Agency \\
\hline CMTS & Committee on the Marine Transportation System \\
\hline COTP & Captain of the Port \\
\hline DHS & Department of Homeland Security \\
\hline DOT & Department of Transportation \\
\hline EEI & Essential Elements of Information \\
\hline EPA & Environmental Protection Agency \\
\hline $\mathrm{FCC}$ & Federal Communications Commission \\
\hline FEMA & Federal Emergency Management Agency \\
\hline GDP & gross domestic product \\
\hline HSIN & Homeland Security Information Network \\
\hline HUD & US Department of Housing and Urban Development \\
\hline IDR & Infrastructure Development and Recovery \\
\hline MARAD & Maritime Administration \\
\hline MIST & mobile integrated survey team \\
\hline MTS & Marine Transportation System \\
\hline MTSRU & Marine Transportation System Recovery Unit \\
\hline NAIS & Nationwide Automatic Identification System \\
\hline
\end{tabular}




$\begin{array}{ll}\text { NDRF } & \text { National Defense Reserve Fleet } \\ \text { NGS } & \text { National Geodetic Survey } \\ \text { NOAA } & \text { National Oceanic and Atmospheric Administration } \\ \text { NOS } & \text { National Ocean Service } \\ \text { OR\&R } & \text { Office of Response and Restoration } \\ \text { RIAT } & \text { Resilience Integrated Action Team } \\ \text { RRF } & \text { Ready Reserve Force } \\ \text { SSC } & \text { Scientific Support Coordinator } \\ \text { USACE } & \text { US Army Corps of Engineers } \\ \text { USCG } & \text { US Coast Guard } \\ \text { USVI } & \text { US Virgin Islands }\end{array}$




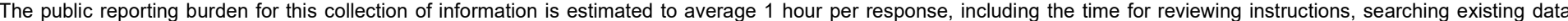

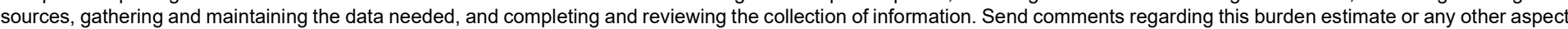

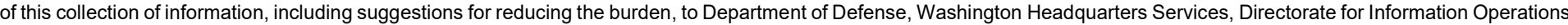

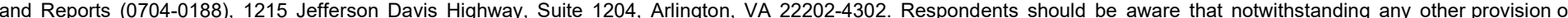
law, no person shall be subject to any penalty for failing to comply with a collection of information if it does not display a currently valid OMB control number. PLEASE DO NOT RETURN YOUR FORM TO THE ABOVE ADDRESS.

\begin{tabular}{l|l|l}
\hline $\begin{array}{l}\text { 1. REPORT DATE } \\
\text { July } 2021\end{array}$ & $\begin{array}{l}\text { 2. REPORT TYPE } \\
\text { Final Report }\end{array}$ & 3. DATES COVERED (FrOm - To)
\end{tabular}

\section{TITLE AND SUBTITLE}

2017 Hurricane Season: Recommendations for a Resilient Path Forward for the Marine

Transportation System

5a. CONTRACT NUMBER

5b. GRANT NUMBER

5c. PROGRAM ELEMENT NUMBER

031391

6. AUTHOR(S)

Katherine Chambers, Joshua Murphy, and Kathryn McIntosh

5d. PROJECT NUMBER

WIC7839F5

5e. TASK NUMBER

5f. WORK UNIT NUMBER

7. PERFORMING ORGANIZATION NAME(S) AND ADDRESS(ES)

Coastal and Hydraulics Laboratory

US Army Engineer Research and Development Center

3909 Halls Ferry Road

Vicksburg, MS 39180-6199

9. SPONSORING/MONITORING AGENCY NAME(S) AND ADDRESS(ES)

US Army Corps of Engineers

Washington, DC 20314-1000

\section{PERFORMING ORGANIZATION REPORT NUMBER \\ ERDC/CHL SR-21-2}

\section{DISTRIBUTION/AVAILABILITY STATEMENT}

Approved for public release; distribution is unlimited.

\section{SUPPLEMENTARY NOTES}

Funding Acct Code U4368911; AMSCO Code 031391

\section{ABSTRACT}

In October 2017, the Coordinating Board of the US Committee on the Marine Transportation System (MTS) tasked the MTS Resilience Integrated Action Team (RIAT) to identify the impacts, best practices, and lessons learned by federal agencies during the 2017 hurricane season. The RIAT studied the resiliency of the MTS by targeting its ability to prepare, respond, recover, and adapt to and from disruptions by turning to the collective knowledge of its members. Utilizing interagency data calls and a targeted workshop, the RIAT gauged the disruptive effect of the 2017 hurricane season and how Hurricanes Harvey, Irma, and Maria affected the operating status of at least 45 US ports across three major regions.

This report identifies recommendations to better understand how the MTS can prepare for future storms and identifies activities by federal agencies that are contributing towards resilience. Such actions include hosting early pre-storm preparedness meetings, prioritizing communication between agencies and information distribution, and maintaining or updating existing response plans. Recommendations also target challenges experienced such as telecommunication and prioritization assistance to ports and critical infrastructure. Finally, the report offers opportunities to minimize the impacts experienced from storms and other disruptions to enhance the resilience of the MTS and supporting infrastructure.

\section{SUBJECT TERMS}

Harbors, Hurricane Harvey 2017, Hurricane Irma 2017, Hurricane Maria, 2017, Hurricanes, Inland navigation, Navigation-

Performance, Waterways

16. SECURITY CLASSIFICATION OF:

\begin{tabular}{l|l|l|}
\hline a. REPORT & b. ABSTRACT & c. THIS PAGE \\
Unclassified & Unclassified & Unclassified \\
\hline
\end{tabular}

17. LIMITATION OF ABSTRACT

SAR
18. NUMBER OF PAGES 73 19a. NAME OF RESPONSIBLE PERSON Katherine Chambers

19b. TELEPHONE NUMBER (Include area code) (202) 761-7582 